This is a post-peer-review, pre-copyedit version of an article published in Earthquake Engineering and Structural

Dynamics. The final authenticated version is available online

at: https://onlinelibrary.wiley.com/doi/epdf/10.1002/eqe.3119

\title{
IN SITU FREE-VIBRATION TESTS ON UNRESTRAINED AND RESTRAINED ROCKING MASONRY WALLS
}

\author{
Linda Giresini ${ }^{1}$, Mauro Sassu ${ }^{2}$, and Luigi Sorrentino ${ }^{3}$ \\ ${ }^{1}$ Department of Energy, Systems, Territory and Constructions Engineering, University of Pisa, Largo Lucio Lazzarino, 1, \\ 56100, Pisa, Italy; linda.giresini@unipi.it \\ ${ }^{2}$ Department of Civil, Environmental Engineering and Architecture, University of Cagliari, Via Marengo, 2, 09123 \\ Cagliari, Italy; msassu@unica.it \\ ${ }^{3}$ Department of Structural and Geotechnical Engineering, Faculty of Architecture, Sapienza - University of Rome, via \\ Antonio Gramsci, 53, 00197, Rome, Italy; luigi.sorrentino@uniroma1.it
}

In the out-of-plane assessment of rocking walls, a relevant and yet uncertain aspect is the influence of energy dissipated during motion due to impacts and restraints, such as a floor or tie rods. Therefore, in situ rocking tests on unrestrained and restrained unreinforced masonry walls, made of composite (rubble + blockwork) masonry, were performed and analyzed. The restraint is given by steel springs of assigned stiffness, simulating a floor connected to full-scale $\left(4 \times 1 \times 0.6 \mathrm{~m}^{3}\right)$ specimens from a dismantling building. The specimens are displaced from a static equilibrium position and released, allowing to evaluate energ y dissipation. The coefficient of restitution is estimated as the square root of consecutive peak velocities of the same sign, to take into account non-homogeneities in walls. For unrestrained walls, experimental coefficients of restitution vary between 81 and $88 \%$ of analytical ones, confirming the latter as conservative. For restrained configurations, experimental coefficients of restitution are between 74 and $83 \%$ of analytical values of unrestrained walls. Hence, an additional energy damping can be ascribed to the springs. Equivalent viscous damping ratios of a non-linear rocking system are calculated by considering a velocity logarithmic decrement, resulting between 6 and 8\% (unrestrained condition) and between 8 and 10\% (restrained condition). An analytical formula is proposed for estimating the coefficient of restitution for restrained walls if the dynamic properties of the unrestrained wall and the horizontal restraint are known. Finally, the relevance of a refined estimation of energy dissipation is discussed by means of numerical time history analyses.

\section{KEYWORDS}

dynamics of rigid blocks, out-of-plane behavior, horizontal restraint, coefficient of restitution, asymmetric wall, damping ratio.

\section{INTRODUCTION}

Behavior of existing masonry buildings during earthquakes is frequently characterized by the response of some of their parts [1]. Such local behavior can be investigated by considering limit analysis and/or rocking approaches. For what concerns the first ones, collapse mechanisms are analyzed to define force and displacement capacities of walls and masonry arches [2], for which strengthening by means of traditional and innovative techniques [3,4] improves also the global structural behavior $[5,6]$. Rocking approaches generally apply when dealing with out-of-plane modes. The out-of-plane response of walls is a relevant issue because, compared to in-plane failure, out-of-plane failure has more severe consequences for people both inside and outside the construction [7-9]. Out-of-plane response is markedly influenced by vertical restraints due to transverse walls, with a frictional interlocking possibly preventing motion [10-12]. If interlocking is not present or is overcome, interaction with transverse walls can be modeled with a bed of springs [13] or by considering one-sided rocking with a lower coefficient of restitution [14]. However, when a wall is restrained only at the base or at the base and at the top, the out-of-plane main response is frequently a rocking one, which is sensitively influenced by ground motion features and system geometry parameters. Several studies were performed to understand to what extent ground motion features and system geometry affect the response [15-21]. 
One of the main issues under debate when facing rocking is energy dissipation. The well-known coefficient of restitution, ratio of velocity just after impact by velocity right before it, is used to damp oscillations and it is computed ased $n$ the conservation of angular momentum [22-24]. Several experimental tests show that such analytical previsions usually underestimate energy dissipation [25-28]. With specific reference to masonry and laboratory campaigns, for fired clay and tuff brickwork the ratio of experimental to analytical coefficients of restitution was about 95\% [26], and two double leaf masonry walls made of approximately dressed stone units with low quality mortar have shown corresponding mean values in the range 95-98\% [27]. Nonetheless, in situ tests on full-scale specimens, obtained by real masonry buildings, have not yet been carried out.

Moreover, in practical cases URM walls are connected to floors, which generally furnish a deformable restraint to the wall. Numerical and analytical models have been proposed for a monolithic or two-body wall with a flexible spring at the top [2932], a single laboratory test campaign has been carried out [33], and experimental tests have been performed on timber diaphragms to assess their in-plane characteristics [34-36]. However, no in situ tests have been performed on free vibrations of full scale walls restrained at the top and rocking about their base corners, and such tests are the objective of this paper. Section 2 presents the experimental setup and tests on individual components, namely masonry and restraint. Section 3 illustrates the tests of the unrestrained and restrained walls. Section 4 and 5 describe the method to correlate results to energy dissipation and damping, proposing an analytical approach for estimating the coefficient of restitution for a restrained wall, given the dynamic characteristics of the horizontal restraint and of the wall. Finally, numerical time-history analyses are performed in Section 6 to highlight the relevance of a refined estimation of energy dissipation.

\section{OVERVIEW AND TESTS ON COMPONENTS}

\section{Test setup}

The free vibrations of three unreinforced masonry walls (Figure 1a) were investigated in two configurations: (i) free-standing and (ii) horizontally restrained by deformable springs close to the top. All walls were tested in the unrestrained condition, whereas wall \#3 was also tested in bilateral restrained configuration. The walls rocked out of plane as might occur to unreinforced masonry façades under earthquake induced inertia forces. Configuration (i) is also representative of parapets, altars, statues, artistic assets, etc., while (ii) is illustrative of rocking walls connected to flexible diaphragms or steel tie rods. The tested walls, made of rubble masonry having specific weight $w \approx 19 \mathrm{kN} / \mathrm{m}^{3}$, were cut from the façade of a building in a hospital complex nearby Pisa (Italy), deemed to demolition. The cutting process, performed by means of a $1500 \mathrm{~mm}$ diameter circular saw (Figure 1b), caused a limited spalling of corners in each wall. The lateral cuts were made to isolate the specimens from adjacent masonry. At the top of the wall a larger amount of masonry was removed, by means of core drilling, in order to allow wall uplifting without arching action. Clay block masonry $\left(w \approx 8 \mathrm{kN} / \mathrm{m}^{3}\right)$ was added to the window splays to obtain rectangular horizontal-section specimens (Figure 2). New independent blockwork panels supported the loads previously carried by the walls.

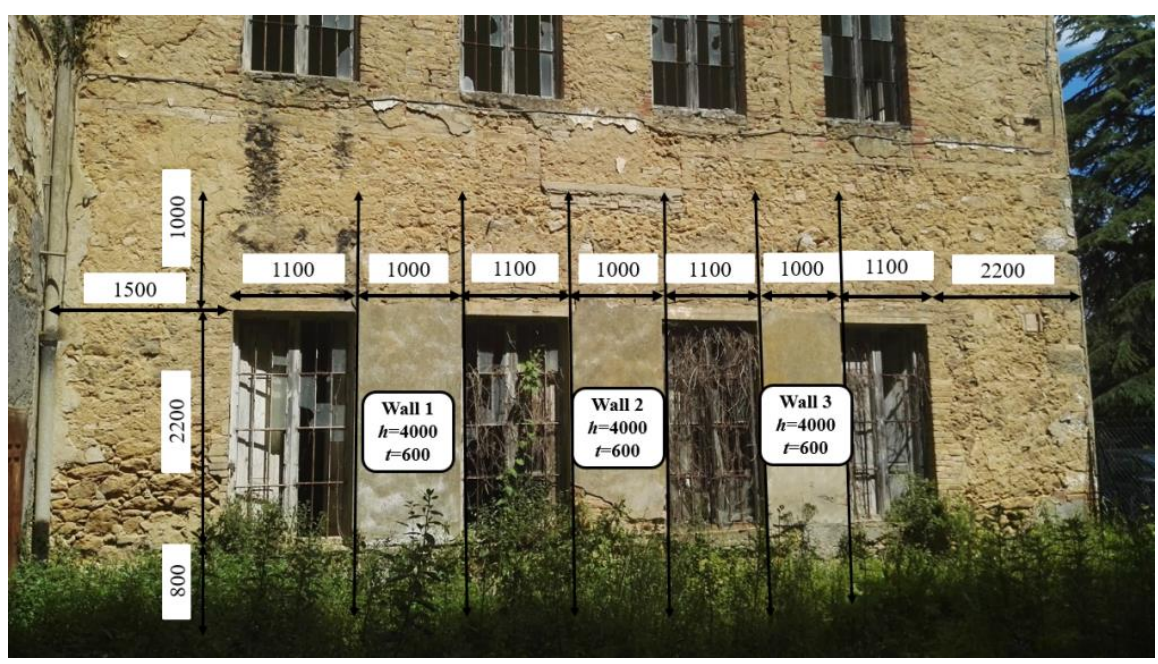

(a)

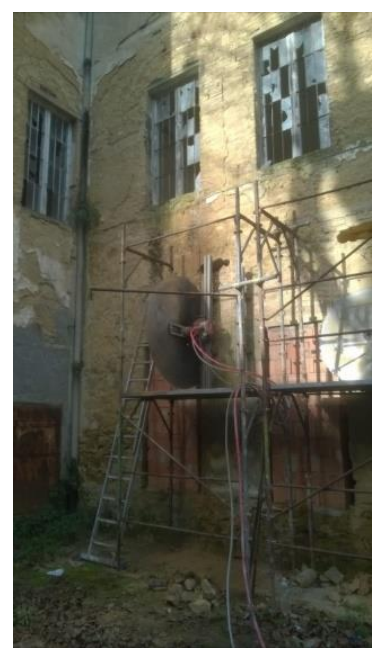

(b)

Figure 1 Tested rubble masonry walls: specimen identification and approximate measures in mm (a) and cutting process (b) 
The wall inhomogeneity requires establishing geometric and mass parameters, such as radius vectors and inertia moments, about left pivot point $O_{l}$ or right pivot point $O_{r}$, separately (Figure 2). These parameters are presented in Table 1. Equivalent volume and equivalent width are calculated homogenizing clay blockwork to rubble masonry.

A scaffolding system, present on both external and internal sides of the walls, acted as safety structure against overturning and as reaction frame for imposing the initial displacement (Figure 3a-b). This displacement was induced by a steel wire rope, tensioned by a manual lever winch and the corresponding axial force was measured, in some tests, by a load cell.
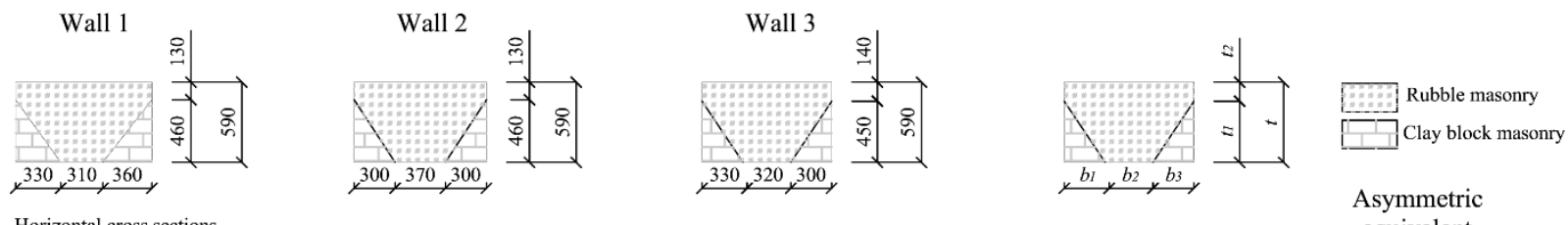

Horizontal cross sections
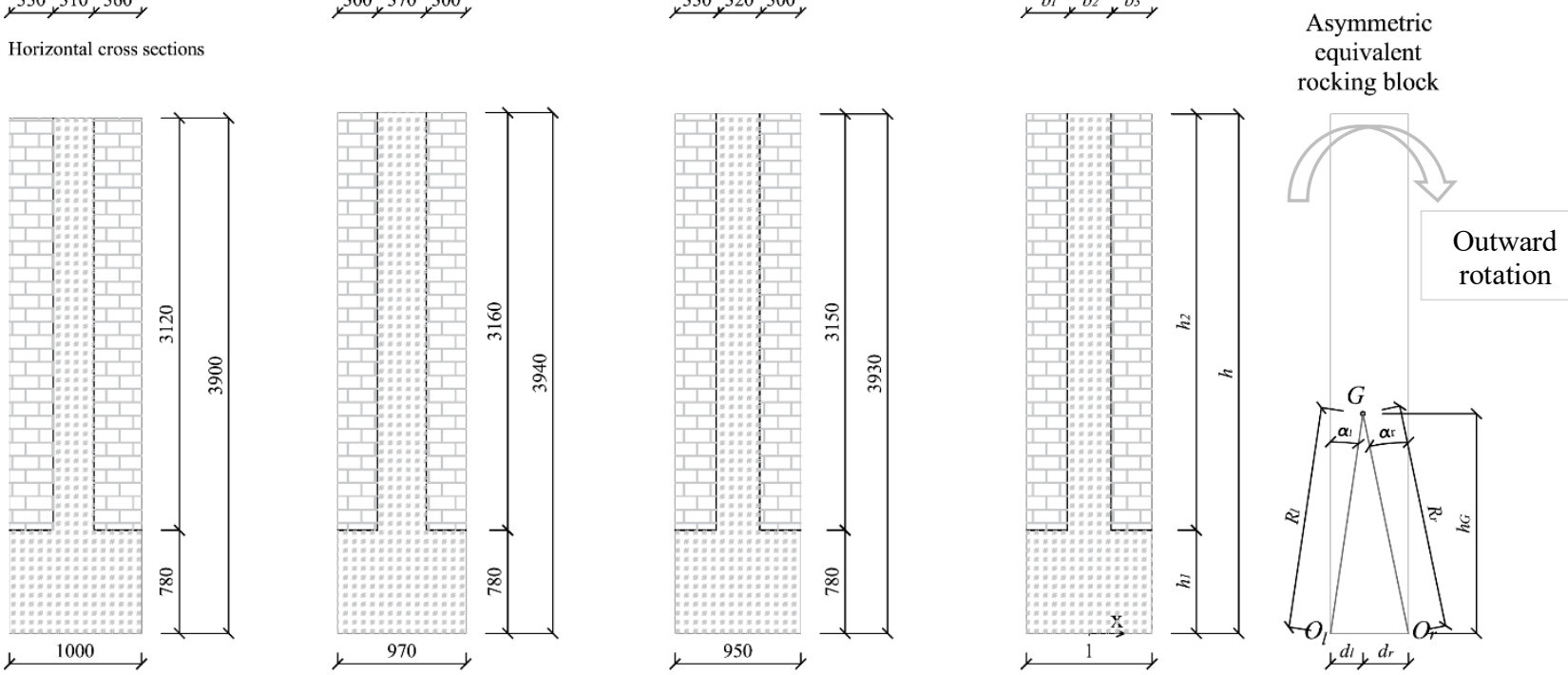

Internal views

Figure 2 Geometric features of the tested walls (all lengths in $\mathbf{m m}$ ).

Table 1 Geometric features and equivalent parameters for the composite masonry walls (symbols explained in Figure 2 and $I o$ inertia moment around $O$ ). RM: rubble masonry, CBM: clay block masonry.

\begin{tabular}{|l|r|r|r|}
\hline WALL \# & $\mathbf{1}$ & $\mathbf{2}$ & $\mathbf{3}$ \\
\hline Volume RM $\left[\mathrm{m}^{3}\right]$ & 2.30 & 2.25 & 2.20 \\
\hline Volume CBM $\left[\mathrm{m}^{3}\right]$ & 0.50 & 0.44 & 0.45 \\
\hline Equivalent RM volume $\left[\mathrm{m}^{3}\right]$ & 2.51 & 2.44 & 2.39 \\
\hline Weight $[\mathrm{kN}]$ & 47.68 & 46.33 & 45.42 \\
\hline$h_{G}[\mathrm{~m}]$ & 1.894 & 1.921 & 1.896 \\
\hline$d_{r}[\mathrm{~m}]$ & 0.315 & 0.313 & 0.314 \\
\hline$d_{l}[\mathrm{~m}]$ & 0.275 & 0.277 & 0.276 \\
\hline$\alpha_{r}[\mathrm{rad}]$ & 0.165 & 0.161 & 0.164 \\
\hline$\alpha_{l}[\mathrm{rad}]$ & 0.144 & 0.143 & 0.144 \\
\hline$R_{r}[\mathrm{~m}]$ & 1.921 & 1.946 & 1.922 \\
\hline$R_{l}[\mathrm{~m}]$ & 1.914 & 1.941 & 1.916 \\
\hline$I_{O r}[\mathrm{kN} \mathrm{m} \mathrm{s}]$ & 19.602 & 19.957 & 18.749 \\
\hline
\end{tabular}




\begin{tabular}{|l|l|l|l|} 
& & & \\
$I_{O l}\left[\mathrm{kN} \mathrm{m} \mathrm{s}^{2}\right]$ & 19.563 & 19.923 & 18.715 \\
\hline
\end{tabular}

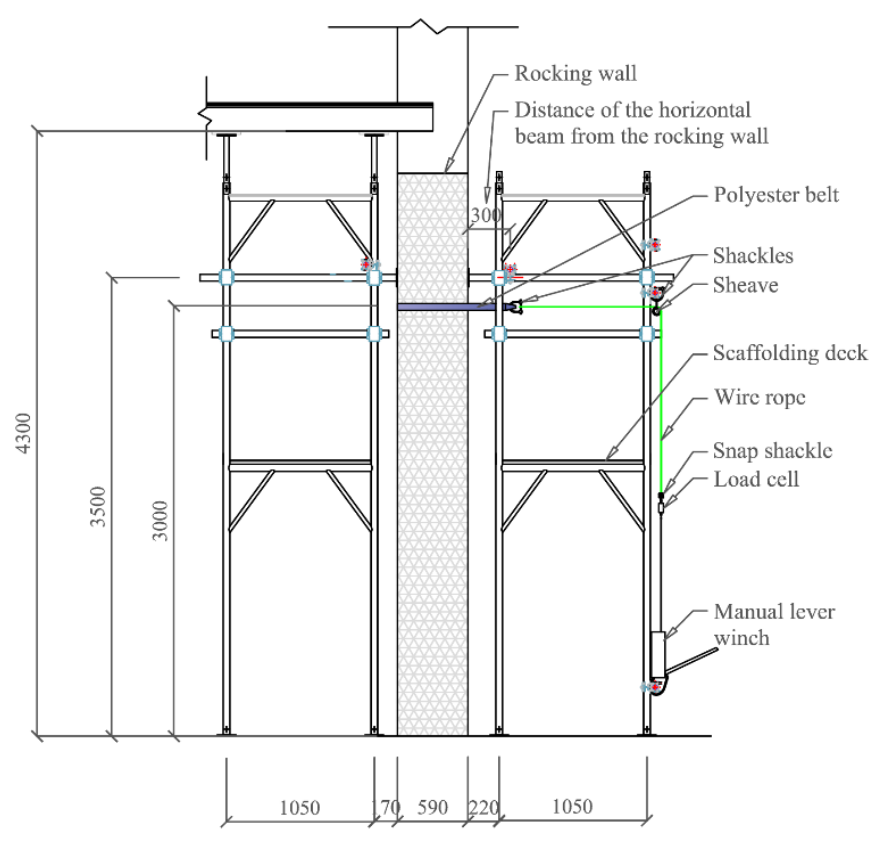

(a)

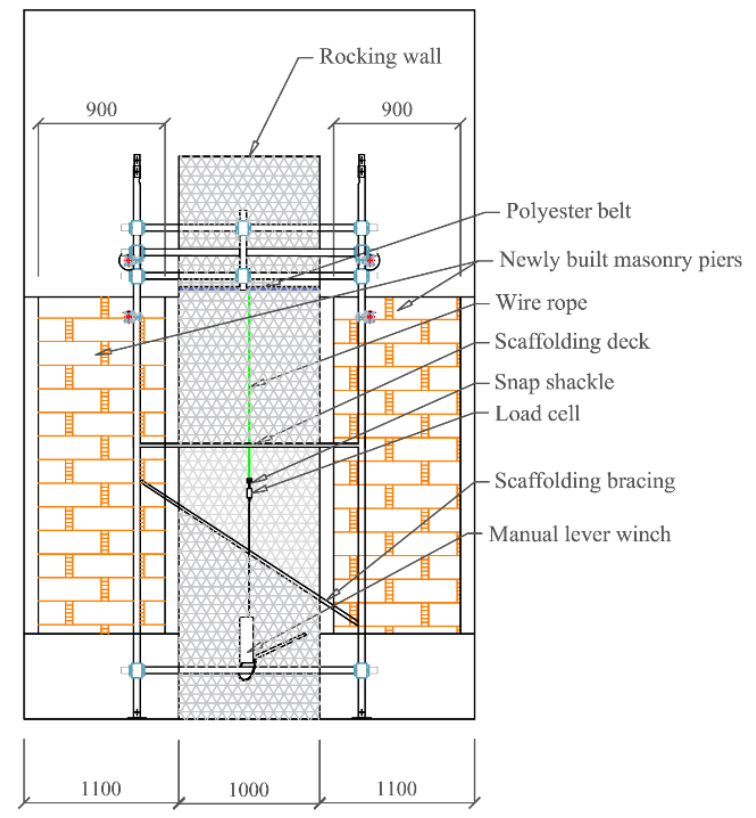

(b)

Figure 3 Experimental test setup of unrestrained rocking wall: section (a) and frontal view (b) - All lengths in mm.

The experimental setup for the restrained configuration is displayed in Figure 4a. The horizontal restraints are made of two + two pairs of springs (Figure 4b). Each pair of springs was connected to the scaffolding by a steel chain (Figure 4c-d), whose buckling prevented the contribution of the two pairs under compression. As will be shown in the following, the chain was much stiffer than the springs, and therefore assumed as rigid during motion. The springs were attached to a polyester band located as close as possible to the wall corner (Figure 4b), to engage almost axially the band whose stiffness is much larger of that of the springs. In fact, the deformation displacement just before release, captured in Figure 4c, is sensibly related to spring elongation. Again, to avoid any slack, a separate polyester band was connected to the rope used to impose the initial displacement to the wall (Figure 4b). Therefore, in the following, it will be assumed that the polyester band attached to the springs is rigid.

Due to time and field experimental setup limitations, related to the demolition schedule, the out of plane displacement was monitored at a control point, located $3000 \mathrm{~mm}$ above the rocking hinge (Figure 5a), only by means of a high-frequency video camera and, at critical times, manually with a laser meter. In the same point the steel wire rope was connected to the wall. The control point was set at $2840 \mathrm{~mm}$ above the rocking hinge in the case of the restrained wall for better positioning of the horizontal springs. During free vibrations only accelerations were measured, at a cut-frequency of $200 \mathrm{~Hz}$, by means of three pairs of DYTRAN accelerometers (model 7521A2) placed on the internal face of walls at three heights: 750, 2300 and 3600 $\mathrm{mm}$ (Figure 5b), to verify that the only degree of freedom activated was rotational [26]. The lack of high-frequency measurements of displacements is not considered crucial for the meaningfulness of the tests because, compared to forced vibrations, free vibrations present a smoother time history. Moreover, energy dissipation of rocking systems is related to velocity thus requiring only one integration.

\section{Material properties of rubble masonry}

The rubble masonry of the building to which the tested walls belong is made of lime mortar and irregular natural stone units, whose length varies from approximately 50 to more than $200 \mathrm{~mm}$. During a previous campaign on the same building [37], this masonry underwent double flat jack test, mortar penetrometer test, diagonal compression test and twin panel test. The related mechanical properties of walls are summarized in Table 2. 
The double flat jacks test highlighted a strong non-linear behavior, variable with the tested specimen size. Unfortunately, the test did not allow determining reliable values of the elastic modulii, because performed over a small volume of masonry (with respect to the average stone-unit size) disturbed by the cuts. Mortar strength delivered by penetrometer test seems compatible with masonry strength delivered by double flat jacks test. Indeed, in case of rubble masonry with units much stronger than mortar, the latter largely influences the composite strength [38]. The failure under the diagonal compression test showed the formation of a compressive strut between the loading plates, after the formation of two tension cracks separating the strut from the rest of the panel. Therefore, the test allowed the estimation of both tensile strength and compressive strength along the strut direction. Given the chaotic nature of the masonry under consideration, compressive strength along the strut was considered representative of that along a vertical direction. The equivalent tensile strength, as well as Young's and shear elastic modulii were estimated by means of the twin panel test, a shear-compression test performed on two adjacent panels belonging to the same wall, horizontally loaded by a jack spanning between the panels but vertically loaded by two different forces [37]. Each panel acted at the same time as test specimen and reaction element, with the different levels of axial forces delivering two sets of data. By the combined use of strain-gages along different directions, the macroscopic elastic modulii of the panels were estimated as $E=1900-3000 \mathrm{MPa}$ and $G=1100 \mathrm{MPa}$, respectively.

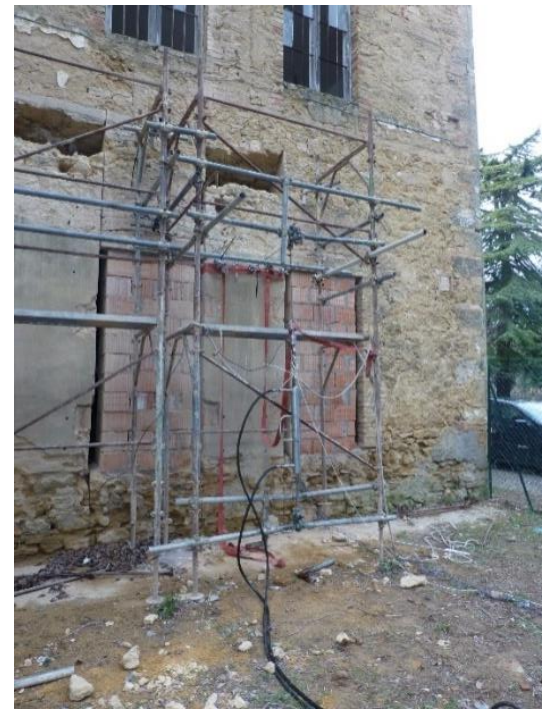

(a)

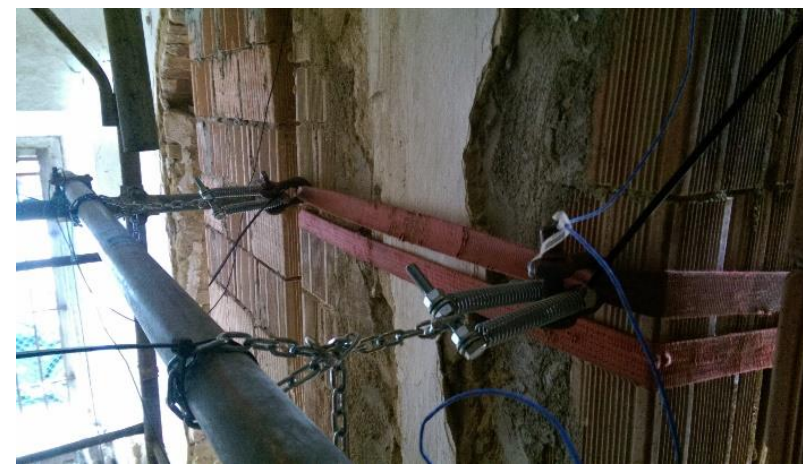

(c)
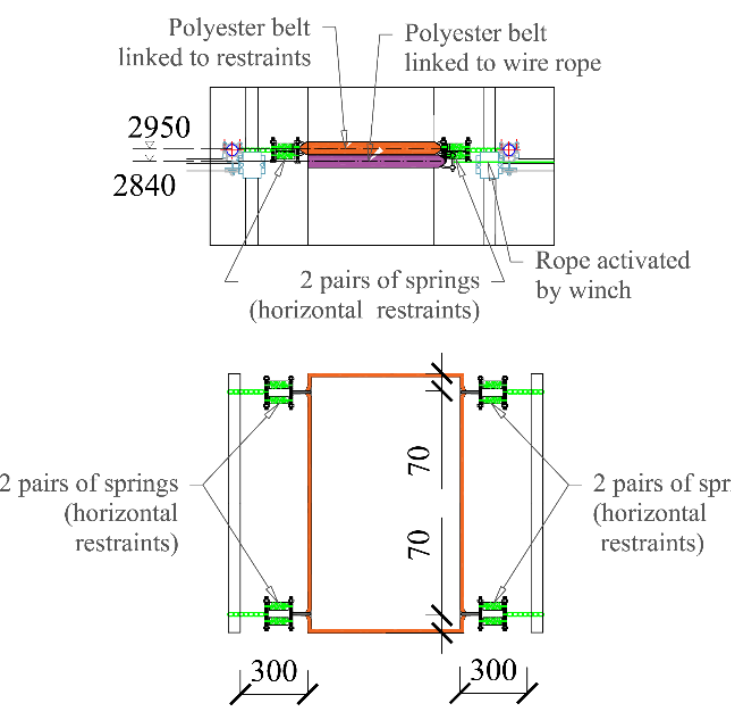

(b)

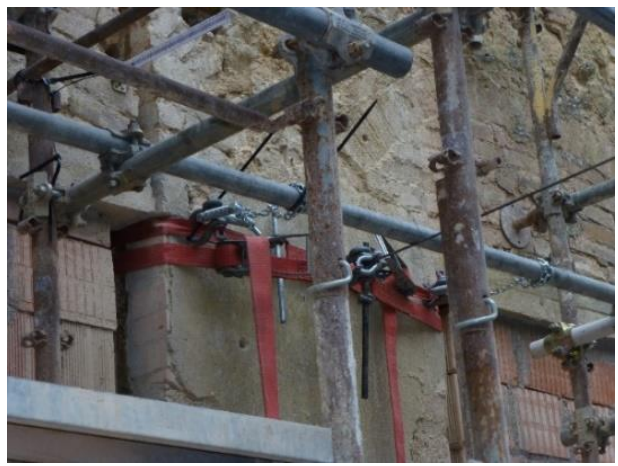

(d)

Figure 4 Wall \#3 restrained by a system of horizontal springs and chains: general view (a), vertical and horizontal sections - all lengths in $\mathbf{m m}(\mathrm{b})$, views inside before release (c) and outside (d) the building. 


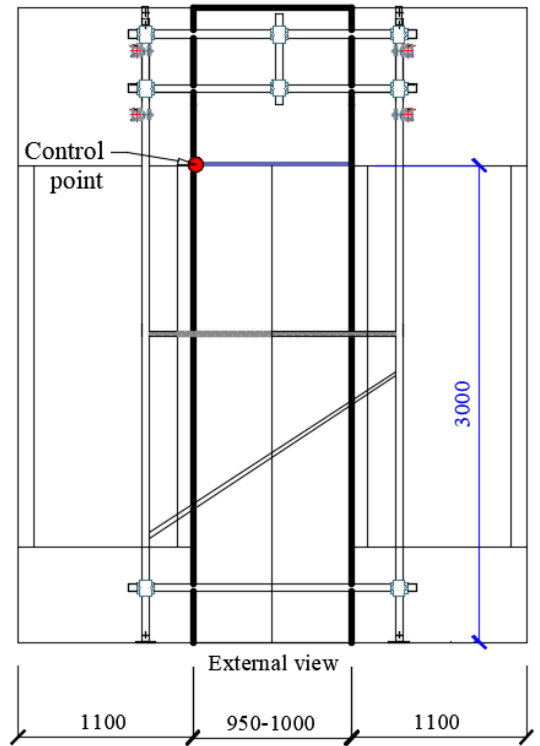

(a)

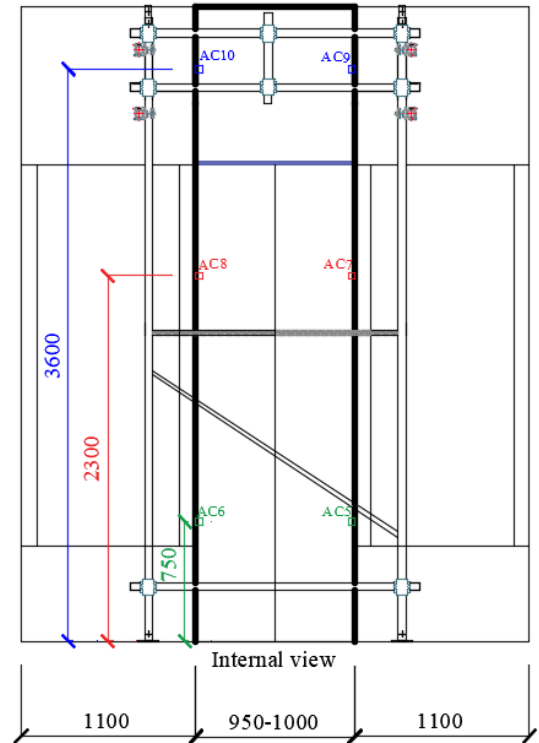

(b)

Figure 5 Control point position (unrestrained condition) (a); instrumentation setup: $2 \times 3$ accelerometers on the internal face of the wall (b). All lengths in $\mathbf{m m}$.

Table 2 Material properties of the rubble masonry [37]. $f_{j}=$ mortar compressive strength, $\sigma\left(f_{j}\right)=$ related standard deviation; $f_{m, e l}=$ masonry elastic strength; $f_{m, u l}=$ masonry ultimate strength; $f_{t}=$ masonry tensile strength; $\boldsymbol{E}=$ masonry Young's modulus, $\boldsymbol{G}=$ masonry shear modulus

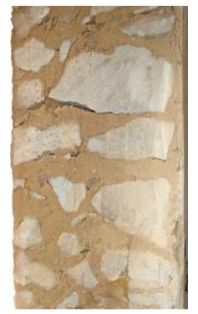

\begin{tabular}{lccccccc} 
Test & $f_{j}[\mathrm{MPa}]$ & $\begin{array}{c}\sigma\left(f_{j}\right) \\
{[\mathrm{MPa}]}\end{array}$ & $\begin{array}{c}f_{m, e l} \\
{[\mathrm{MPa}]}\end{array}$ & $\begin{array}{c}f_{m, u l} \\
{[\mathrm{MPa}]}\end{array}$ & $\begin{array}{c}f_{t} \\
{[\mathrm{MPa}]}\end{array}$ & $\begin{array}{c}E \\
{[\mathrm{MPa}]}\end{array}$ & $\begin{array}{c}G \\
{[\mathrm{MPa}]}\end{array}$ \\
\hline PNT-G mortar penetrometer & 0.83 & 0.03 & - & - & - & - & - \\
\hline Double flat jack & - & - & $\begin{array}{c}0.4- \\
0.8\end{array}$ & $0.80-1.20$ & - & $400-800$ & $150-300$ \\
\hline Diagonal compression & - & - & & $0.78-0.80$ & 0.055 & - & - \\
\hline Twin Panel Test & - & - & & & 0.051 & $1900-3000$ & 1100
\end{tabular}

In order to roughly evaluate how much these experimental material properties are representative of the national building stock they could be compared with those recommended by the Commentary to the Italian Building Code [39]. Therein compressive strength values $\left(f_{m, u l}=1.0-1.8 \mathrm{MPa}\right)$ are somewhat larger than Table 2 values, whereas tensile strength $\left(f_{t}=0.030-0.048 \mathrm{MPa}\right)$ and elastic modulii (suggested values: $E=690-1050 \mathrm{MPa}$ and $G=230-350 \mathrm{MPa}$ ) are smaller.

\section{Structural properties of horizontal restraints}

Stiffness of timber diaphragms can vary over a wide range, depending on geometry, timber properties, sheating, nailing details, connections to walls and direction of load with respect to joists. Diaphragms can act as a horizontal restraint for outof-plane loaded walls and be characterized by an equivalent spring of stiffness $k_{H}$ that can be related to the diaphragm shear stiffness, $G \cdot t$, defined as equivalent shear modulus times diaphragm thickness [36]. Given a horizontal diaphragm of span $L$ and depth $B$ subjected to an in-plane horizontal force $F_{H}$, the equivalent spring normal stiffness can be derived from the midspan displacement $u_{H}$ and the shear stiffness $G \cdot t$ as [36]:

$$
k_{H}=\frac{F_{H}}{u_{H}}=8 G \cdot t \frac{B}{L}
$$

In situ and laboratory tests allowed to identify values of both shear and equivalent spring normal stiffness for vintage or new timber diaphragms (

Table 3). When only shear stiffness was given a conventional $4 \times 4 \mathrm{~m}^{2}$ diaphragm has been assumed to compute spring stiffness. 
Table 3 Values of shear stiffness $G \cdot t$ and equivalent spring stiffness $k_{H}$ from building codes and experimental tests (loading direction perpendicular, P., or parallel, Pa., to joists, J.).

\begin{tabular}{|c|c|c|c|c|c|}
\hline$G \cdot t$ & $B$ & $L$ & $k_{H}$ & \multirow{2}{*}{ Floor type } & \multirow{2}{*}{ Reference } \\
\hline$(\mathrm{kN} / \mathrm{m})$ & $(\mathrm{m})$ & (m) & $(\mathrm{kN} / \mathrm{m})$ & & \\
\hline 350 & 4.0 & 4.0 & 2800 & single straight sheating (both P.J. and Pa.J.) & [40] \\
\hline 424 & 4.0 & 4.0 & 3392 & flooring boards P.J.,initial values-lab tests & [36] \\
\hline 1872 & 4.0 & 4.0 & 14976 & flooring boards and plywood panels P.J.-lab tests & $"$ \\
\hline 260 & 4.0 & 4.0 & 2080 & flooring boards P.J., final values-lab tests & $"$ \\
\hline 1204 & 4.0 & 4.0 & 9632 & flooring boards and plywood panels loaded P.J.-lab tests & $"$ \\
\hline 185 & 4.0 & 4.0 & 1480 & Pa.J. (minimum value)-lab tests & [34] \\
\hline 134 & 4.0 & 4.0 & 1072 & P.J. (minimum value)-lab tests & $"$ \\
\hline 156 & 4.6 & 9.6 & 598 & vintage diaphragms P.J. (some flooring discontinuous)-in situ tests & [41] \\
\hline 137 & 5.7 & 9.6 & 651 & vintage diaphragms P.J. (most flooring discontinuous)-in situ tests & $"$ \\
\hline 73 & 10.4 & 5.5 & 1104 & new diaphragms P.J.-lab tests & $"$ \\
\hline 106 & 5.5 & 10.4 & 449 & new diaphragms Pa.J.-lab tests & $"$ \\
\hline 155 & 5.6 & 9.6 & 723 & vintage diaphragms P.J.-in situ tests & [35] \\
\hline 171 & 4.7 & 9.6 & 670 & " & \\
\hline 85 & 5.6 & 9.6 & 397 & vintage diaphragms loaded P.J.at critical drift level (3\%) & " \\
\hline 70 & 4.7 & 9.6 & 274 & " & " \\
\hline
\end{tabular}

The design of the horizontal restraint used in tests described hereinafter was governed by the aim of inducing ample rotations in the wall while developing a force compatible with the scaffolding reaction capacity, limited by the tight time frame of the in situ experiments. Therefore, a target stiffness between $15-20 \mathrm{kN} / \mathrm{m}$ was assumed, which was much lower than values in Table 3, but comparable to the flexible spring $\left(k_{H}=37 \mathrm{kN} / \mathrm{m}\right)$ assumed by Penner and Elwood [33] for the only laboratory vibrations tests to date on walls with an elastic restraint at the top. Several types of horizontal restraints have been conceived and tested, but here only a double spring + chain assembly and its components, are described.

\section{Single spring}

Two types of single springs were considered: SS-A, with maximum commercial length of $67 \mathrm{~mm}$, and SS-B, with corresponding length of $187 \mathrm{~mm}$. A single SS-A spring has a yield force just above $0.7 \mathrm{kN}$, much lower of that of the SS-B spring (Figure 6a), but feasible for the reaction scaffolding frame. The stiffness of SS-A spring is about $4.1 \mathrm{kN} / \mathrm{m}$ and is slightly larger than that of a SS-B spring, equal to about $3.4 \mathrm{kN} / \mathrm{m}$. Two couples of SS-A springs were necessary to get the target stiffness.

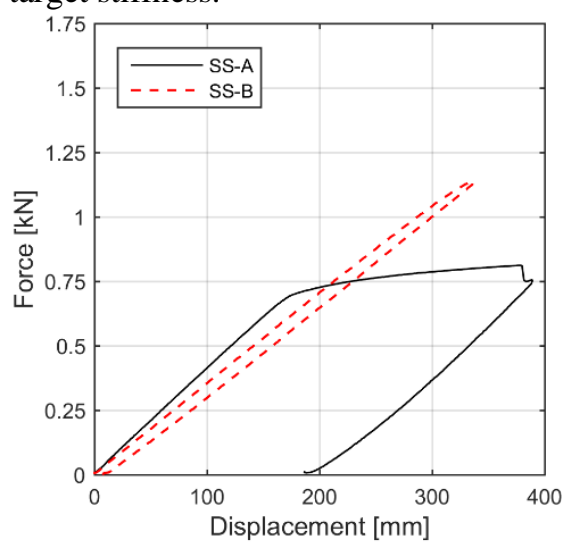

(a)

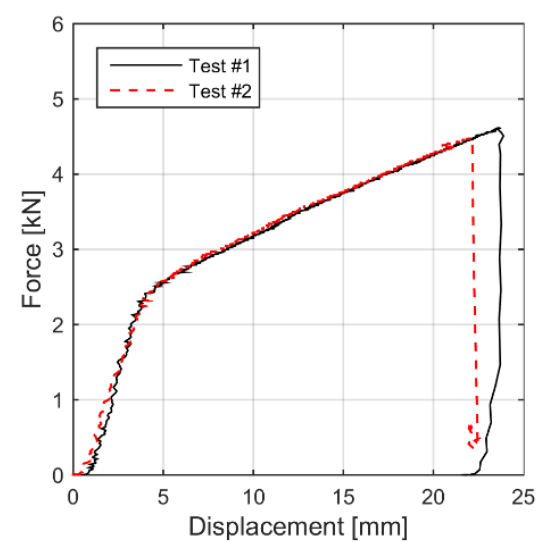

(b)

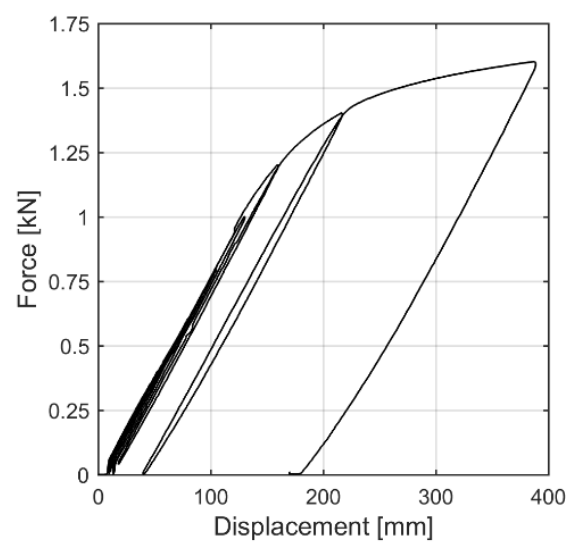

(c)

Figure 6 Force-displacement law of: Single spring (SS-A and SS-B) (a); articulated link chain (b); double spring and chain assembly (c). 


\section{Chain}

The chain used in the assembly, whose links were made from a $3.3 \mathrm{~mm}$ diameter coil, was meant to avoid any contribution of the springs under compression. However, the chain should remain elastic when the springs were under tension. Therefore, a ten-link chain was tested in tension (Figure 6b). The constitutive law highlighted that elastic behavior ended at about 2.20 $\mathrm{kN}$, well beyond the strength of a double spring. The chain stiffness was about $650 \mathrm{kN} / \mathrm{m}$, almost 100 times that of a double spring.

\section{Double spring and chain assembly}

The adopted restraint was composed of two assemblies of two springs coupled by two 12-mm diameter bolts (Figure 7a). A chain was linked to the bolt with a shackle of $5 \mathrm{~mm}$ coil diameter. The tensile test of a single assembly was performed beyond yielding (Figure 6c). The elastic phase corresponds to an assembly stiffness of about $8.5 \mathrm{kN} / \mathrm{m}$, with a yield force of about $1.2 \mathrm{kN}$ and a ductility factor exceeded 2.5 .

The damping of the assembly was evaluated by means of a free vibrations test, during which an initial load was applied at the bottom of the system (Figure 7b) and then suddenly removed by means of a snap shackle (Figure 7c). The initial elongation in the first test was $110 \mathrm{~mm}$ and in the second one was $145 \mathrm{~mm}$, both close to the elastic limit (Figure 6c). By computing the damping ratio using the displacement logarithmic decrement, average values of 0.5 and $1.4 \%$ were obtained, respectively.

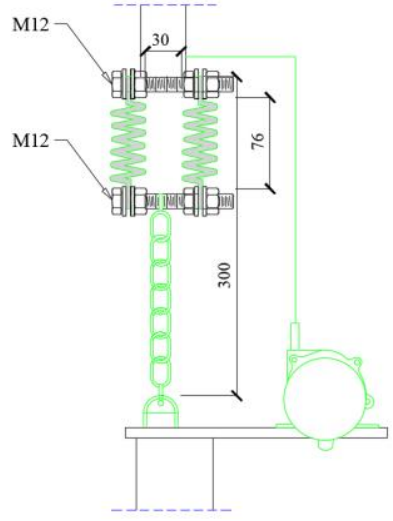

(a)

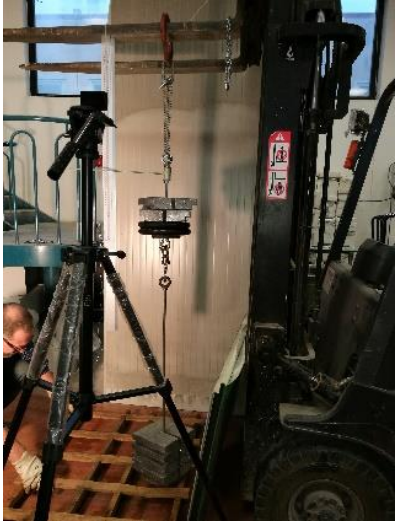

(b)

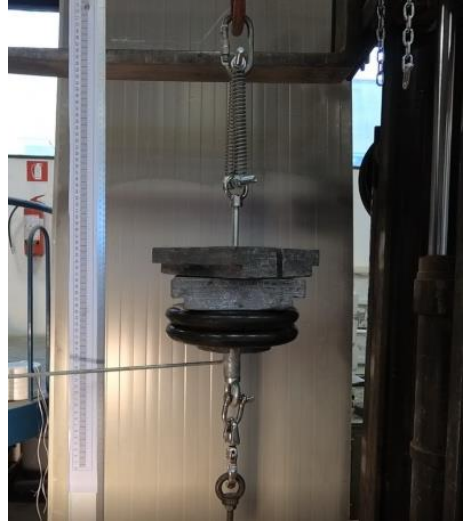

(c)

Figure 7 Double spring and chain assembly (a, all lengths in $\mathbf{m m}$ ); experimental setup for evaluation of damping (b); close up of assembly, additional mass, and snap shackle to initial load (c).

\section{IN SITU WALL TESTS}

\section{Summary of dynamic tests}

A summary of the dynamic tests performed on the three walls is reported in Table 4-Table 6. Twenty-seven tests were performed on the walls, but only nine of them were considered valid. Indeed, the tests affected by ineffective recording or by overturning against a too close safety the scaffolding or or by a residual out-of-plane plumb displacement larger than $10 \mathrm{~mm}$ at the control point (corresponding to a permanent out-of-plumb rotation of the wall) were disregarded. Such out-of-plumb, observed in walls \#2 and \#3, was due to debris that during the motion penetrated in the lateral vertical cuts, which had insufficient width. Unfortunately, all cuts were performed for all walls at the same time during specimens preparation, rather than for each wall after the previous one was tested. Therefore, it was not possible to adjust the size of the lateral cuts based on hard experience. However, in order to have pure rocking, the debris within the cuts were removed before performing a new test, and in the end satisfactory oscillations were obtained.

Among the release techniques discussed in [26], the following ones were used. Wall \#1 was connected to a steel chain (different from that used in the restraint assembly) pulled until failure, whereas a snap shackle was applied for walls \#2 and \#3 (Figure 8). Both systems involved a degree of disturbance at the beginning, either because the deformation energy of the chain was suddenly discharged, or because the chord used to open the snap shackle was pulled.

After initial displacement was imposed (at force $F_{i}$ ) and the wall released, the wall vibrated without cracking or rocked after cracking. The wall was inspected before each test, with special attention close to its base where cracking was expected. When 
rocking occurred the base section clearly opened and closed multiple times highlighting the complete penetration of the crack. In no case sliding at the base was observed. Eight tests on wall \#1 were carried out, labeled from U1-A to U1-H where U stands for unrestrained (free) condition. Only tests U1-B, U1-G and U1-H could be considered valid and are discussed in the following. Wall \#2 was tested ten times, but only the last two time histories were considered valid, due mainly to residual displacement at the end of vibration. Wall \#3 was tested seven times in free conditions and three in restrained (prefix R) conditions. After the third test the load cell, used only for this wall, hit the ground and damaged itself. Therefore, only displacements were measured. For wall \#3, four tests were considered valid.

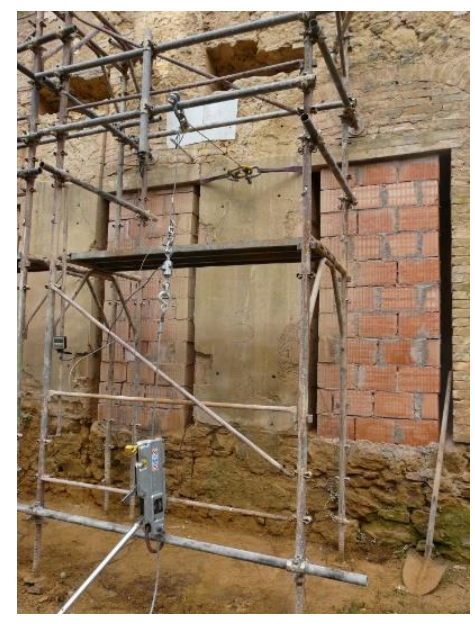

(a)

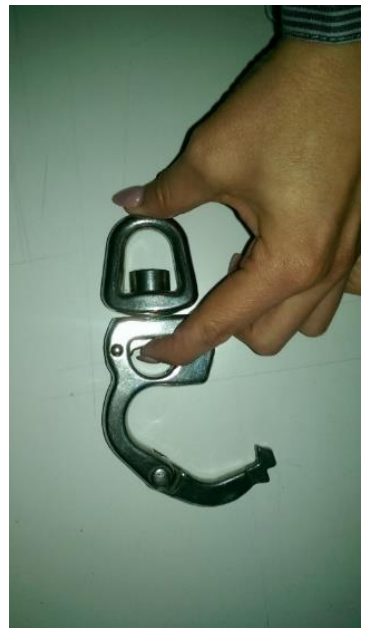

(b)

Figure 8 Snap shackle: connected to the wire rope (a); in opened position (b).

Table 4 Summary of dynamic tests. Wall \#1, released by chain failure.

Test Notes

U1-A Chain failure without wall cracking, signal noise due to close-by machinery

U1-B Wall vibration without cracking

U1-C Zero wall displacement due to inadequate force application

U1-D Horizontal crack at wall base without chain failure, wall free to rock

U1-E Rocking behavior, overturning against scaffolding

U1-F Rocking behavior, overturning against scaffolding

U1-G Rocking behavior

U1-H Rocking behavior

Table 5 Summary of dynamic tests. Wall \#2, released by chain and snap shackle (alternatively).

Test Notes

U2-A Horizontal crack at wall base, chain close to failure (visible deformation), wall stuck due to debris in the lateral cut surfaces

U2-B Wall displacement close to zero, wall stuck due to debris in the lateral cut surfaces

U2-C Wall displacement close to zero, wall stuck due to debris in the lateral cut surfaces, yielding of transverse beam of scaffolding

U2-D Overturning against scaffolding; at the end of the unloading phase $20 \mathrm{~mm}$ residual displacement of control point

U2-E At release wall stuck due to debris in the lateral cut surfaces

U2-F At release wall rocked with a $20 \mathrm{~mm}$ residual displacement

U2-G At release wall rocked with a $15 \mathrm{~mm}$ residual displacement

U2-H Rocking behavior

U2-I Rocking behavior

U2-L Rocking behavior with a $15 \mathrm{~mm}$ residual displacement 
Table 6 Summary of dynamic tests. Wall \#3, released by snap shackle.

Test Notes

U3-A Load cell. $F_{i}=4.00 \mathrm{kN}$. Horizontal crack at wall base. At release, wall stuck due to debris in the lateral cut surfaces

U3-B Load cell. $F_{i}=4.15 \mathrm{kN}$. Rocking behavior.

U3-C Load cell. $F_{i}=6.30 \mathrm{kN}$. Rocking behavior. Load cell damaged at the end of the test

U3-D Rocking behavior

U3-E Rocking behavior

U3-F Rocking behavior. At the end of the test, wall stuck due to debris in the lateral cut surfaces

U3-G Rocking behavior with substantial residual rotation due to debris in lateral cut surfaces

R3-A Restrained condition, due to addition on both sides of two assemblies of double springs and chain. Rocking behavior, malfunction of the data recording system after release

R3-B Restrained condition. Rocking behavior

R3-C Restrained condition. Rocking behavior

\section{Data elaboration and integration process}

As already mentioned, due to time and field experimental setup limitations, only acceleration time histories were recorded and the need of their processing to have velocity time histories arose. The ATHs were processed and integrated with a specifically developed MATLAB code [42], based on the works of Ribeiro et al. [43] and Slifka [44]. First of all, the vibration signal expressed by an acceleration time history should have zero mean, whereas the recorded acceleration time histories had a slight direct current (DC) bias. This bias involved unacceptable numeric errors that accumulated in the integration and delivered a linear trend to velocity. The DC bias could be eliminated by means of a proper high-pass filter, although this step was sensitive to adopted parameters. Therefore, a Fast Fourier Transform (FFT) was used as an alternative, and amplitudes related to frequencies below a threshold value were set constant. As proposed in [43], a Fourier coefficient index equal to 3 was adopted. An example of unprocessed and FFT processed ATHs are displayed in Figure 9a.

Afterwards, the inverse FFT was calculated and from that, with a trapezoidal integration, velocity was obtained. Analogously, a FFT of the velocity time history was computed and amplitudes related to frequencies below the same threshold value were set constant. Finally, the inverse FFT was calculated to get the ultimate velocity time history (Figure 9b). These velocity time histories were used to estimate the coefficient of restitution as discussed hereinafter.
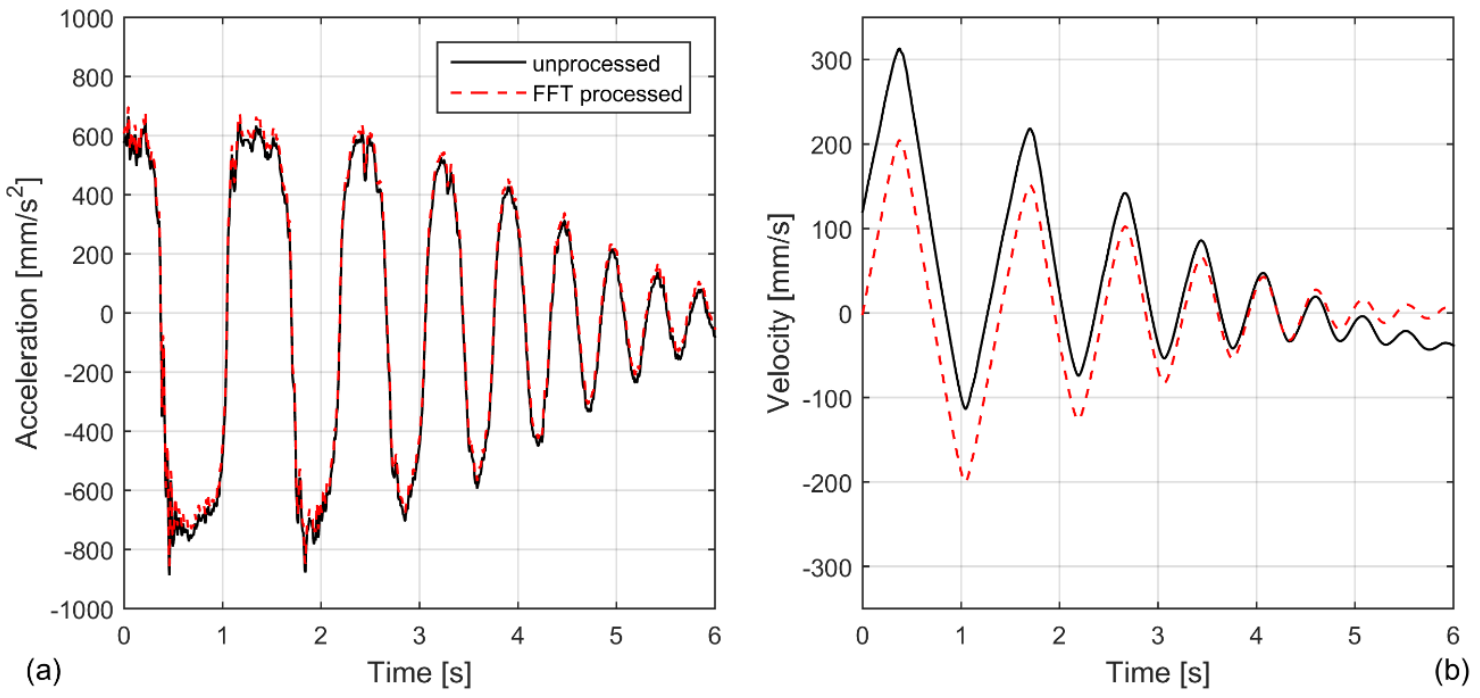

Figure 9 Example of unprocessed and processed acceleration (a) and velocity (b) time-histories. Test U1-G.

\section{Tests on uncracked unrestrained wall}

Whereas for walls \#2 and \#3 the displacement initially applied already induced cracking at the base, for wall \#1 rocking occurred only in the fourth test (Table 4). In the second test, U1-B, an uncracked frequency of vibration $3.58 \mathrm{~Hz}$ was recorded. 
Uncracked wall \#1 could be assimilated to a cantilever and, assuming homogeneity both within the section and along the height, the fundamental frequency of vibration $f_{1}$ is [45]:

$$
f_{1}=\frac{C_{1}}{2 \pi l^{2}} \sqrt{\frac{E I}{q}}
$$

where $C_{1}=3.516$ (constant for given boundary conditions), $E=$ Young's modulus, $I=$ axial moment of inertia about section bending axis, $q=$ mass per unit length, and $l=$ wall height. With the data of Table 1 and the measured frequency, Young's modulus $E$ is about $615 \mathrm{MPa}$, a value that is too low compared to material tests. The poor agreement is reasonably related to the model neglecting gravity force.

Padoussis and Des Trois Maisons [46] derived a model for a heavy vertical cantilever under free vibrations, for which they define the following dimensionless term:

$$
\gamma=\frac{q g}{E I} l^{3}
$$

where $q=$ gravity acceleration. In the case under examination, based on measured frequency, the circular frequency is equal to $22.49 \mathrm{rad} / \mathrm{s}$ from which it is graphically possible to estimate $\gamma=0.06$. With the geometrical data of Table 1, a Young's modulus of $2467 \mathrm{MPa}$ can be computed, which falls almost at the center of the range estimated by means of the twin panel test (Table 2).

\section{Pre-cracking and post-cracking force-displacement relationship in static conditions}

An outward force $F$ was monotonically applied to the wall at $H_{F}=2.84 \mathrm{~m}$, and the corresponding rotation $\theta$ (Figure 10a) was computed based on measured displacement of control point. The interaction with lateral structures, induced by debris present in the vertical cuts of walls \#2, 3, prevented not only uncracked vibrations, but also the estimation of corresponding stiffness. On the contrary, such stiffness can be appraised for wall \#1, which was unrestrained, as approximately equal to $152 \mathrm{kN} / \mathrm{m}$ before cracking and $85 \mathrm{kN} / \mathrm{m}$ after cracking.

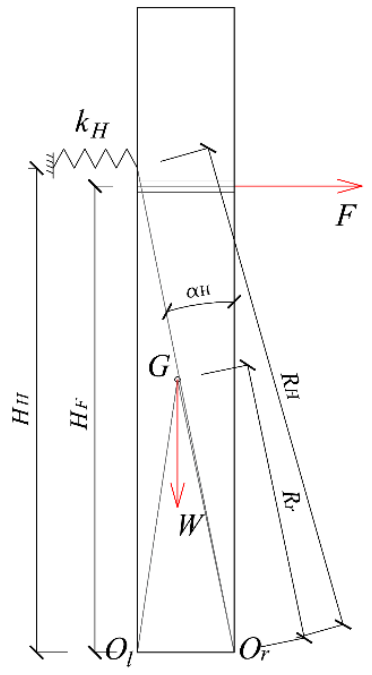

(a)

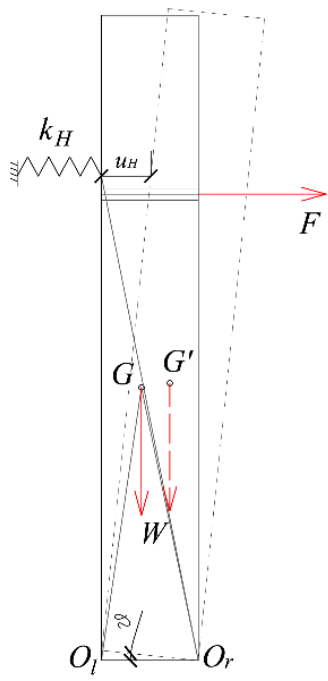

$O_{l}-\ldots O_{r}$

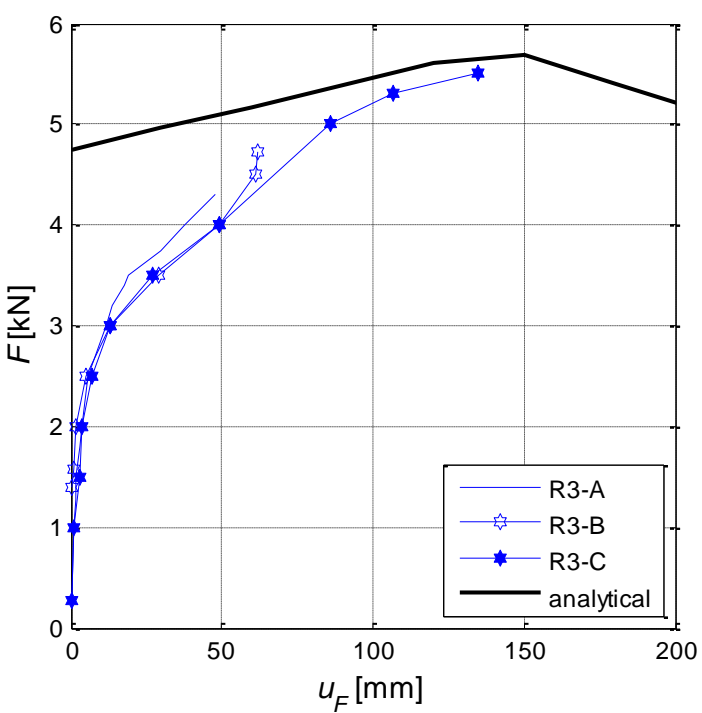

(b)

Figure 10 Application of static force (a) and force-displacement relationship of the restrained cracked wall \#3 (Table 4) compared to the analytical law (Eq.(4) and Eq. (5)) (b).

As for the restrained condition, test repetition showed a reasonably systematic behavior (Figure 10b). Force, F, -displacement, $\mathrm{u}_{\mathrm{F}}$, experimental curves can be compared to that of a wall rocking rigidly while restrained by spring of combined stiffness $k_{H}$. A simple equilibrium condition around the right pivot point Or gives:

$$
F=\frac{W R_{r} \sin \left(\alpha_{r}-\theta\right)+k_{H} u_{H} R_{H} \cos \left(\alpha_{H}-\theta\right)}{H_{F} \cos \theta}
$$

where $W$ = wall self-weight, $R_{r}\left(\alpha_{r}\right)=$ radius vector (slenderness angle) of the wall about right pivot point (Figure 10a), $u_{H}=$ horizontal displacement of the restraint, $R_{H}\left(\alpha_{H}\right)=$ radius vector (slenderness angle) of the restraint about right pivot point. 
For $\mathrm{u}_{\mathrm{H}}>\mathrm{u}_{\mathrm{H}, \mathrm{y}}$ (subscript $\mathrm{y}=$ reference to the yielding of the horizontal restraint) the force exerted by the restraint is assumed constant and equal to $H_{y}$. Thus, the force-displacement relationship becomes:

$$
F=\frac{W R_{r} \sin \left(\alpha_{r}-\varphi\right)+H_{y} R_{H} \cos \left(\alpha_{H}-\varphi\right)}{H_{F} \cos \varphi}
$$

It is worth to emphasize that Eq .(4) and Eq. (5) consider the geometrical and mechanical non-homogeneities of the wall illustrated in Figure 2, and therefore the geometrical values in Table 1 need to be considered. This relationship is in reasonable agreement with the experimental results around peak force, as shown in Figure $10 \mathrm{~b}$.

\section{EXPERIMENTAL ASSESSMENT OF ENERGY DISSIPATION}

In principle, a rocking free-standing block exhibits energy dissipation only due to impacts (Housner's modelo) or due to impacts and a continuous energy dissipation mechanism. The latter can be due to (i) rocking on a flexible base hinge, (ii) flexure within the block, (iii) sliding at the rocking surface [47,48]. In the case under examination, a continuous energy could be due only to (i), since any wall experienced visible damages in its body (therefore excluding ii) and exhibited translational motion at its foundation (therefore excluding iii). However, for this case, a straightforward determination of the coefficients of restitution assuming only the ratio of velocities at impact is more straightforward and of immediate comprehension.

One can then assume, in a simplified way, that rocking motion is characterized by impacts between body and base, to which energy dissipation is associated. Within such framework a coefficient of restitution $e$, ratio of velocities after and before impact, can be defined as a function of geometry alone. If the body is homogeneous and symmetric the following equation applies [22]:

$$
e=1-\frac{3}{2} \sin ^{2} \alpha
$$

where $\alpha_{l}=\alpha_{r}=\alpha$ (Figure 2) due to symmetry hypothesis. If the wall is not homogeneous, a different energy dissipation has to be taken into account depending on the rotation sign. Indeed, imposing the conservation of angular momentum, the following equation can be obtained:

$$
e_{l}=1-\frac{m R_{l}^{2}}{I_{O, l}}\left(1-\cos 2 \alpha_{l}\right)
$$

valid for an inward rotation (symbols refer to Figure 2 and Table 1), whereas for an outward rotation one has:

$$
e_{r}=1-\frac{m R_{r}^{2}}{I_{O, r}}\left(1-\cos 2 \alpha_{r}\right)
$$

The analytical values obtained after Eq. (7) and Eq. (8) are listed in Table 7. It is worth mentioning that without the addition of the clay blockwork the analytical values would have changed just about $1 \%$.

From an experimental standpoint, estimating velocity just before and after an impact is challenging. However, if it is accepted that energy is lost only at impact, one could compute the coefficient of restitution as the ratio of the absolute peak velocities separated by one half cycle (Figure 9b) obtaining the values in Figure 11. These coefficients are, as expected, lower than unity in almost all cases, but there are exceptions and there is a significant scatter. Such trends are reasonably due to the inhomogeneity of the walls (Figure 2), which makes the impact asymmetric and suggest to calculate two values of the coefficient of restitution, $e_{l}$ and $e_{r}$, as the square root of the ratio of same sign peak velocities, as already proposed by Costa et al. [27]. The square root is needed because two impacts occur in the full cycle separating the two peaks. The smoother and more stable trends of Figure 12 are obtained, therefore supporting the opportunity of considering two distinct values rather than just one. Experimental values are lower than the analytical ones. Moreover, restrained wall values are lower than unrestrained wall ones, suggesting that the restraint involves also an additional source of energy dissipation.

Test average coefficients of restitution are listed in Table 7 by considering only positive peaks $\left(e_{\text {exper,r }}\right)$, or only negative peaks $\left(e_{\text {exper }, l}\right)$. The sixth column of the table reports $e_{\text {exper }, l-r}$, the average values considering all the coefficients of restitution $e_{l}$ and $e_{r}$ at each rebound. In the same table, the analytical values obtained after Eq. (7) and Eq. (8) are listed. The analytical expression always overestimates the actual coefficient of restitution. The ratio between average experimental values and analytical values lies between 81 and $88 \%$ (average $84.3 \%$ ) for the unrestrained walls, which is markedly lower than in laboratory literature mentioned in the introduction.

This result is even more relevant because masonry finite compressive strength reduces the effective rocking base [27]costacompared to the theoretical geometric base shown in Figure 2. Such reduced base would involve a higher analytical coefficient of restitution and thus less energy dissipated than expected based on conservation of angular momentum for impulses passing through cross-section geometric corners. On the other hand, removing the top load from tested walls has reduced the rocking hinge compression zone and it is to be expected that, if rocking involves walls under large axial load, ratio between actual and analytical coefficient of restitutions will be closer to $100 \%$ than observed here. Nonetheless, the average ratio of about $84 \%$, especially in light of finite masonry compressive strength, seems to confirm that impacts alone are not able to explain all damping taking place in rocking bodies and a continuous energy dissipation mechanism must occur. 
The latter can be due to: a) flexure within the block; b) sliding at rocking surface; and c) rocking on a flexible foundation $[47,48]$. In the time histories under examination, flexure and sliding were not observed and only mechanism c) seems plausible, also considering pre-cracking and post-cracking behavior reported in previous sections. A further indication about the presence of an additional source of energy damping is that Although the introduction of an angular velocity proportional damping coefficient has been proposed [47,48], this parameter would need an experimental estimation, hence it is preferred here to reduce the analytical coefficient of restitution.

The ratio between average experimental values of the restrained wall and, for lack of a more adequate model, analytical values of the unrestrained wall lies between 74 and $83 \%$ (average 79.4\%). This reduced value suggests that adding the restraint involves an increase of energy dissipation compared to unrestrained wall.

A slight reduction of the coefficient of restitution is present within each time history in Figure 12, with the only exception of test R3-C. Considering the linear regression of each curve, an angular coefficient between -0.004 and -0.015 is observed. However, when moving from a time-history to the next no systematic trend can be recognized, because $e_{\text {exper, },-r}$ in Table 7 increases for walls $\# 1$ and $\# 2$, and reduces for wall $\# 3$, in both unrestrained and restrained configurations. Most variations are of limited extent and can be considered as inescapable experimental variabilities, as rocking section becomes more polished or on the contrary comparatively larger aggregates are dislocated and change the cross-section profile. Additionally, it is worth emphasizing that, as already shown from Table 4 to Table 6, several tests were performed in addition to those considered valid and explicitly analyzed, thus accumulating a larger deterioration as can probably be expected during a single seismic event. On the other hand, tested walls were non-loadbearing, so horizontal structure masses amounting to a significant fraction of wall masses can induce a larger modification of rocking section than experienced during the tests reported here.

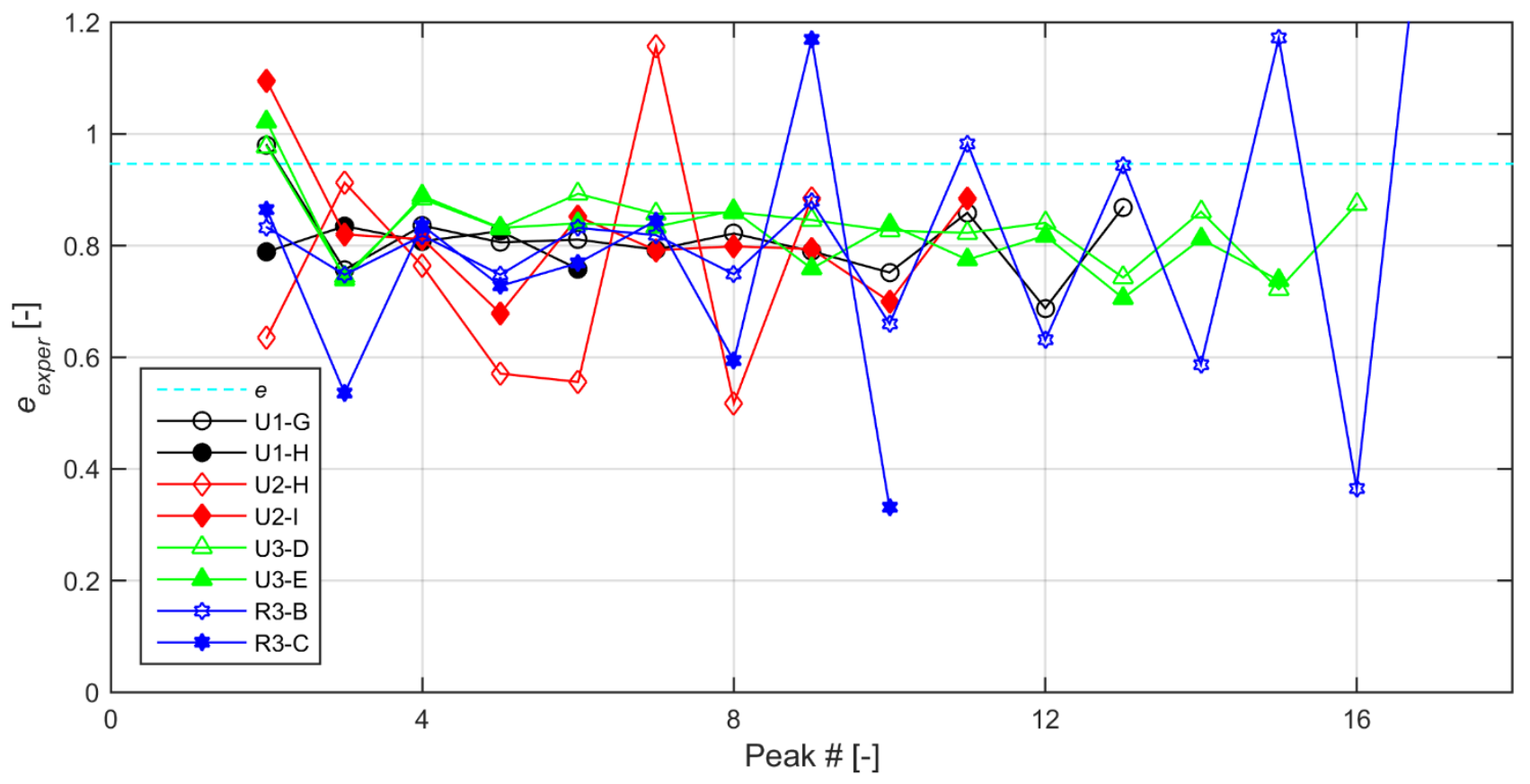

Figure 11 Experimental coefficient of restitution, ratio of absolute peak velocities separated by one half cycle, compared to the analytical one (Eq. (6), computed for an average $\alpha=0.154 \mathrm{rad}$ ). $\mathrm{U}=$ unrestrained wall, $\mathrm{R}$ $=$ restrained wall. 


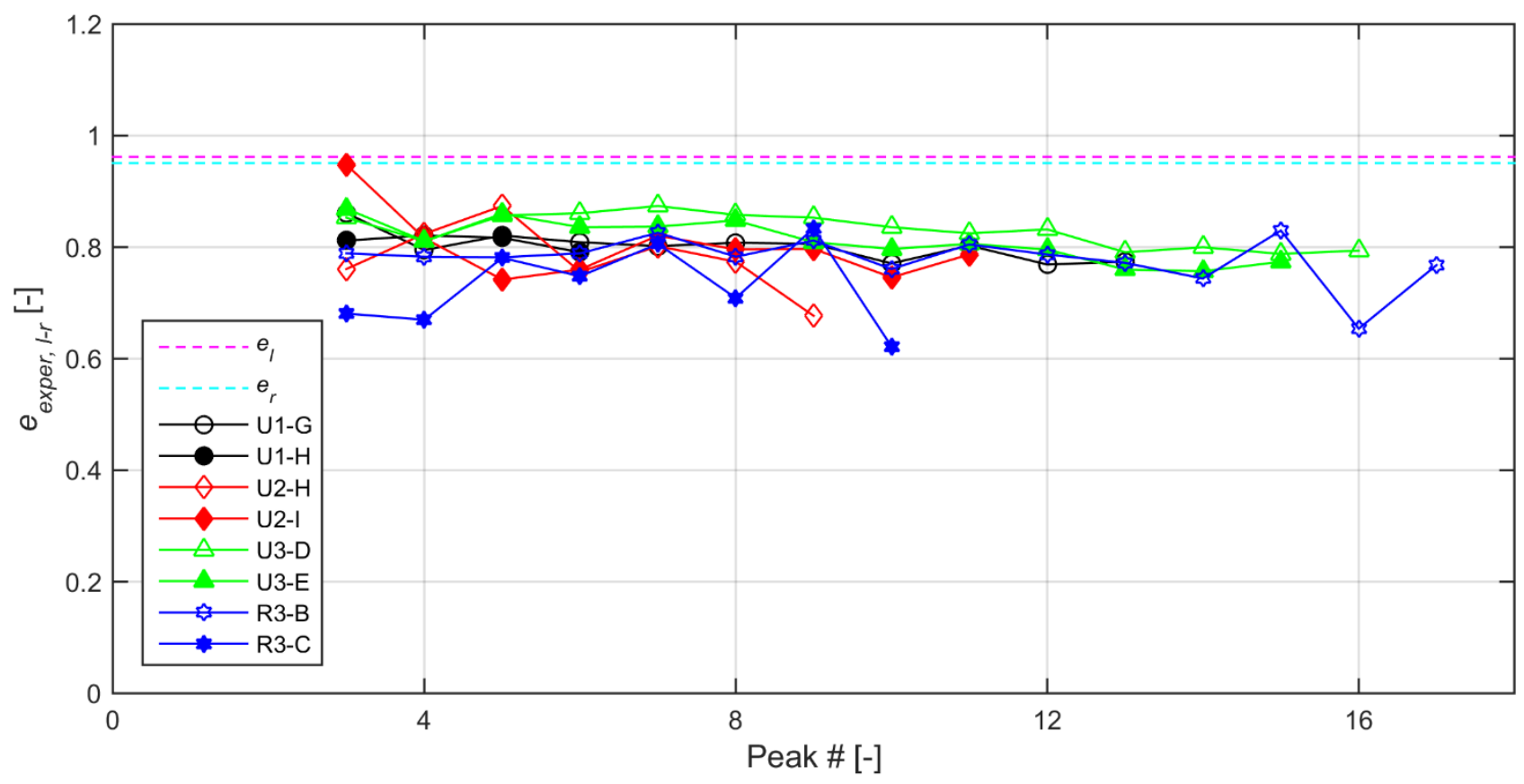

Figure 12 Experimental coefficient of restitution, square root of ratio of peak velocities separated by one full cycle, compared to the analytical ones, $e_{l}$ and $e_{r}((\mathrm{Eq}$. (7) and Eq. (8)). $\mathrm{U}=$ unrestrained wall, $\mathrm{R}=$ restrained wall.

Table 7 Average values of experimental coefficient of restitution, ratio to analytical ones (Eq. (7) and Eq. (8)) and average values of experimental damping ratios (Eq. (9)).

\begin{tabular}{llllccccc} 
& $\begin{array}{c}e_{l} \\
{[-]}\end{array}$ & $\begin{array}{c}e_{r} \\
{[-]}\end{array}$ & $\begin{array}{c}e_{\text {exper, }, l} \\
{[-]}\end{array}$ & $\begin{array}{c}e_{\text {exper }, r} \\
{[-]}\end{array}$ & $\begin{array}{c}e_{\text {exper }, l-r} \\
{[-]}\end{array}$ & $\begin{array}{c}e_{\text {exper }, l} / e_{l} \\
{[\%]}\end{array}$ & $\begin{array}{c}e_{\text {exper, }, r} / \\
e_{r}[\%]\end{array}$ & $\begin{array}{c}\xi_{G M} \\
{[\%]}\end{array}$ \\
\hline U1-G & 0.962 & 0.951 & 0.811 & 0.790 & 0.802 & 84.3 & 83.1 & 7.0 \\
\hline U1-H & 0.962 & 0.951 & 0.814 & 0.806 & 0.817 & 84.6 & 84.8 & 6.7 \\
\hline U2-H & 0.964 & 0.954 & 0.779 & 0.785 & 0.781 & 80.8 & 82.3 & 7.9 \\
\hline U2-I & 0.964 & 0.954 & 0.819 & 0.779 & 0.801 & 85.0 & 81.7 & 7.1 \\
\hline U3-D & 0.962 & 0.951 & 0.834 & 0.833 & 0.834 & 86.7 & 87.6 & 5.6 \\
\hline U3-E & 0.962 & 0.951 & 0.824 & 0.808 & 0.816 & 85.6 & 84.9 & 6.6 \\
\hline R3-B & 0.962 & 0.951 & 0.798 & 0.757 & 0.779 & 82.9 & 79.6 & 7.6 \\
\hline R3-C & 0.962 & 0.951 & 0.775 & 0.709 & 0.731 & 80.6 & 74.5 & 10.0
\end{tabular}

\section{EXPERIMENTAL EQUIVALENT VISCOUS DAMPING}

In numerical analyses, concentrating energy dissipation at impacts requires a careful determination of their occurring, usually involving a variable integration time step. Therefore, Giannini and Masiani proposed in 1990 [49] an harmonic balance procedure to estimate an equivalent viscous damping ratio, $\xi_{G M}$, allowing energy dissipation along the entire time history, according to the following equation:

$$
\xi_{G M}=\frac{2(1-e)}{\pi(1+e)}
$$

More recently and independently Imanishi et al. [50] proposed the following formula for an equivalent viscous damping ratio:

where:

$$
\xi_{I}=\frac{v}{\sqrt{4 \pi^{2}+v^{2}}}
$$

$$
v=\ln \frac{v_{i}}{v_{i+1}}
$$


in which $v_{i}=$ velocity of the control point at $i$-th peak and $v_{i+1}=$ velocity at following peak with same sign. If the coefficient of restitution $e$ is computed based on the experimental ratio $v_{i+1} / v_{i}$, Eq. (9) and Eq. (10) deliver the same results. It is worth emphasizing that the equivalent viscous damping by Giannini and Masiani is different from that discussed by Makris and Konstantinidis [51]. Indeed, that in Eq. (9) is meant to be used in a non linear rocking analysis as an alternative to the coefficient of restitution, whereas that examined by Makris and Konstanitidis is part of a strategy to estimate displacement demand using a conventional elastic response spectrum in an equivalent static analysis.

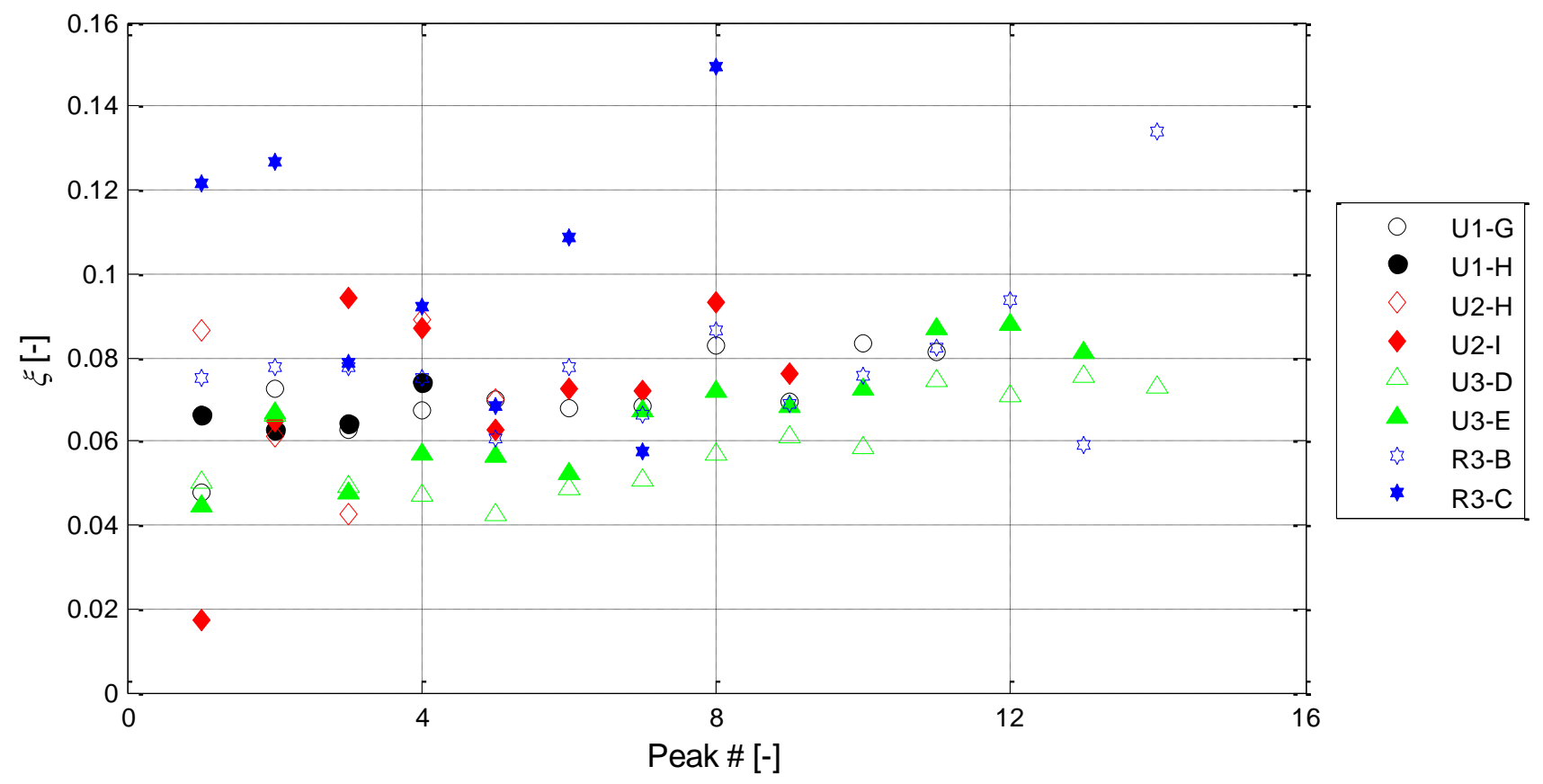

Figure 13 Viscous damping ratios calculated from experimental values of coefficient of restitution (Eq. (9)).

Figure 13 displays the viscous damping ratios obtained from Eq. (9) and experimental VTHs. It is possible to notice that the walls in free conditions have damping ratios between 6 and 8\%. Damping ratios of unrestrained wall \#3 increase by approximately $2 \%$ if restraints are added (Table 7, last column). An equivalent coefficient of restitution, $e_{R}$, for the restrained wall can be estimated from the Giannini and Masiani's [49] formulation with:

$$
e_{R}=\frac{2-\pi \xi_{R}}{2+\pi \xi_{R}}
$$

where $\xi_{R}$ is the damping ratio of the restrained wall. This ratio can be evaluated by considering the wall and viscous restraint acting in parallel, in linear conditions for the sake of simplicity (Figure 14). The dynamic properties of the restrained wall (mass $m_{R}$, damping constant $c_{R}$ and stiffness $k_{R}$ ) are therefore:

$$
m_{R}=m_{w}=\frac{3}{4} m ; \quad c_{R}=c_{H}+c_{w} ; \quad k_{R}=k_{H}+k_{w}
$$

The sub-indexes $H$ and $w$ respectively indicate the horizontal restraint and the wall. The effective mass $m_{w}$ is, for a wall rotating about its base corner approximately, approximately $3 / 4$ of the actual mass [52]. The stiffnesses are obtained from experimental tests $\left(k_{H}\right.$, section 2.3 and $k_{w}$, section 2.4). The damping constant of the horizontal restraint $c_{H}$ can be expressed as:

$$
c_{H}=2 m_{H} \omega_{H} \xi_{H}
$$

where the multiplication factors are taken from experimental tests (section 2.4), and $\omega$ is the circular frequency. In addition, the damping constant associated to the wall is similarly calculated as:

$$
c_{w}=2 m_{w} \omega_{w} \xi_{w}
$$

in this case considering the experimental results of the free-standing wall (Table 7 for $\xi_{w}$ and section 3 for an average natural frequency $\left.\omega_{w}\right)$.

Once the damping constant is known for the restrained condition, the damping ratio $\xi_{R}$ can be calculated as:

$$
\xi_{R}=\frac{c_{R}}{2 m_{R} \omega_{R}}
$$


estimating the circular frequency again from tests or based on stiffness and mass.

Using Eq. (12) and experimental parameters, the coefficient of restitution in restrained condition varies between 0.76 and 0.81 , because rocking wall has an amplitude dependent stiffness. Such values are reasonably close to the 0.76 average value in Table 7 (last two lines, second and third columns). Thus, Eq. (12) allows estimating the coefficient of restitution of a restrained wall when the dynamic properties of the free-standing wall and of the horizontal restraint are available.

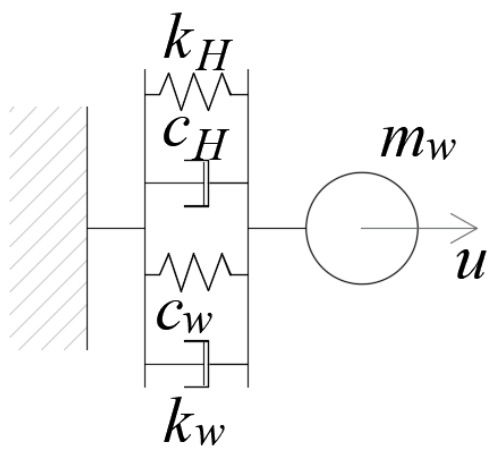

Figure 14 Schematic representation of the wall and viscous restraint acting in parallel.

\section{IMPACT OF EXPERIMENTALLY CALIBRATED ENERGY DISSIPATION ON THE BEHAVIOR OF A RESTRAINED ROCKING WALL}

In order to get a preliminary assessment of the relevance of a finely estimated energy dissipation, one wall was subjected to different earthquake ground motions, considering either the analytical coefficient of restitution or the experimentally calibrated values.

\section{Selection of geometry and input signals}

The overall geometry considered for the numerical rocking analyses was that of wall \#3 (Table 1), but symmetry has been assumed in order to investigate the sole influence of the coefficient of restitution. Hence, the following average parameters were used $R=1.919 \mathrm{~m}$ and $\alpha=0.154 \mathrm{rad}$. A set of six accelerograms was taken from the Engineering Strong Motion Database [53] by selecting one seismic record for each range of Peak Ground Velocity (PGV) of $10 \mathrm{~cm} / \mathrm{s}$, between 0 to $60 \mathrm{~cm} / \mathrm{s}$. The selected accelerograms belong to the event of the Central Italy Earthquakes occurred on October $30^{\text {th }}, 2016$ (06.40 UTC), and their main features are reported in

Table 8. For the unrestrained wall, first the analytical coefficient of restitution (Eq. (6)) was assumed then, based on results presented in Table 7, 85\% of the analytical value has been considered. The same analyses were also performed in restrained conditions, with a bilateral stiffness of $17 \mathrm{kN} / \mathrm{m}$. Again, first a coefficient of restitution equal to $95 \%$ of the analytical one was used, with the 5\% reduction related to the additional energy dissipation granted by the horizontal restraint. Then, the coefficient of restitution is reduced to $80 \%$ of that in Eq. (6), as a combined effect of experimental calibration valid for the unrestrained wall and of horizontal restraint energy dissipation.

Table 8 Earthquake ground motions of the October $3^{\text {th }}, 2016$ Central Italy seismic event [53] used for numerical rocking analyses. PGA: peak ground acceleration, PGV: peak ground velocity, PGD: peak ground displacement.

\begin{tabular}{llrrrr} 
Record ID & Station name & PGA & PGV & PGV/PGA & PGD \\
\hline 1 & & $\left(\mathrm{~cm} / \mathrm{s}^{2}\right)$ & $(\mathrm{cm} / \mathrm{s})$ & $(\mathrm{s})$ & $(\mathrm{cm})$ \\
\hline 2 & AQV & 63.1 & 5.00 & 0.08 & 2.36 \\
\hline 3 & CIT & 319.5 & 15.67 & 0.05 & 9.25 \\
\hline 4 & T1212 & 274.4 & 27.71 & 0.10 & 14.85 \\
\hline 5 & AMT & 521.6 & 37.91 & 0.07 & 6.02 \\
\hline 6 & ACC & 425.9 & 44.11 & 0.10 & 14.16 \\
\hline & T1213 & 779.3 & 60.73 & 0.08 & 12.42
\end{tabular}




\section{Analysis and discussion of results}

The maximum values of dimensionless rocking rotations are listed in Table 9, varying record, boundary conditions and coefficient of restitution. Increasing PGV usually induces a larger response, although few exceptions exist especially for the restrained wall (

Table 8, record 4), probably because correlation between PGV and rocking response has been investigated so far mainly for free-standing blocks [54]. Adding the horizontal restraint almost systematically involves a marked reduction of maximum response, with the exception of record 4 , which has a high PGA value (

Table 8). Finally, the experimentally calibrated coefficient of restitution (third and fifth columns of Table 9) involves a substantially reduced maximum rotation, compared to values of the second and fourth columns. The beneficial effect of an increased energy dissipation was analytically shown by Dimitrakopoulos and DeJong [55], for a rocking body with a vertical viscous damper at the foot. Although the trends in Table 9 should be further investigated with a wider set of geometries, horizontal restraint stiffness and records, they suggest the relevance of a carefully selected coefficient of restitution. Similarly, they highlight how an elastic restraint can markedly reduce the wall response, provided that the horizontal structure is adequately robust and properly connected to the wall. The wall response reduces as the restraint stiffness increases [29-32], but for large stiffness the mechanism may change with the formation of an intermediate hinge [29-32].

Table 9 Maximum values of dimensionless rocking rotations, varying record, boundary conditions and coefficient of restitution (analytical value $e$ according to Eq. (6))

\begin{tabular}{|l|l|l|l|l|}
\hline Boundary condition & \multicolumn{2}{|c|}{ Unrestrained } & \multicolumn{2}{c|}{ Restrained } \\
\hline Coefficient of restitution & \multicolumn{1}{|c|}{$e$} & $0.85 e$ & $0.95 e$ & $0.80 e$ \\
\hline Record ID & $\max (|\theta| / \alpha)$ & $\max (|\theta| / \alpha)$ & $\max (|\theta| / \alpha)$ & $\max (|\theta| / \alpha)$ \\
\hline 1 & 0.000 & 0.000 & 0.000 & 0.000 \\
\hline 2 & 0.071 & 0.036 & 0.043 & 0.013 \\
\hline 3 & 0.316 & 0.169 & 0.002 & 0.001 \\
\hline 4 & 0.227 & 0.187 & 0.230 & 0.106 \\
\hline 5 & 0.463 & 0.257 & 0.081 & 0.041 \\
\hline 6 & overturning & 0.475 & 0.464 & 0.274 \\
\hline
\end{tabular}

\section{CONCLUSIONS}

Increased computational capacity and the formulation of several analytical models have popularized dynamic analyses for rocking mechanisms. However, such models introduce energy dissipation by computing a coefficient of restitution based on the conservation of angular momentum. Limited experimentation has been carried out to verify such formulations, especially in the case of large in situ walls, and this statement is even more true for restrained façades.

This work presented estimations of energy dissipation in unrestrained and horizontally restrained rocking walls, by means of in situ tests on composite (rubble + blockwork) masonry specimens. The horizontal restraint, made of two double spring and chain assemblies, simulated flexible timber diaphragms whose equivalent spring stiffness and damping ratio were obtained from static and dynamic tests. From the rocking tests, coefficients of restitution were calculated by considering consecutive peak velocities of the same sign, to take into account the wall non-homogeneity. The in situ campaign showed that the analytical coefficient of restitution underestimates energy dissipation, with the experimental / analytical ratio being on average approximately equal to $85 \%$. The corresponding ratio for the restrained wall delivers an average of about $80 \%$, suggesting that springs contribute also to energy dissipation. Therefore, analytical models based on the conservation of angular momentum are not accurate and energy dissipation is larger than what already reported for laboratory tests on unrestrained walls. Although it is premature to derive general guidelines, because other masonry types and wall geometries need to be studied, preliminary assessments can be based on reduction values derived from this campaign.

Moreover, an analytical formula is proposed to estimate the coefficient of restitution of a restrained wall when the dynamic properties of the unrestrained wall and of the horizontal restraint can be estimated separately, and this model is able to reasonably capture measured values. 
Finally, numerical rocking analyses show that an accurate estimation of dissipated energy has a relevant impact on vulnerability assessment, avoiding over-conservative estimations. As a consequence, unnecessary interventions can be excluded, with an obvious reduction of costs and averting unwanted strengthening on architectural heritage buildings.

\section{REFERENCES}

1. D'Ayala D, Speranza E. Definition of Collapse Mechanisms and Seismic Vulnerability of Historic Masonry Buildings. Earthquake Spectra 2003; 19(3): 479-509. DOI: 10.1193/1.1599896.

2. Pugi F, Galassi S. Seismic analysis of masonry voussoir arches according to the Italian building code. Ingegneria Sismica 2013; 30(3): 33-55.

3. Alecci V, Focacci F, Rovero L, Stipo G, Stefano M De. Intrados strengthening of brick masonry arches with different FRCM composites: Experimental and analytical investigations. Composite Structures 2017; 176: 898-909. DOI: https://doi.org/10.1016/j.compstruct.2017.06.023.

4. Alecci V, De Stefano M, Focacci F, Luciano R, Rovero L, Stipo G. Strengthening masonry arches with lime-based mortar composite. Buildings 2017; 7(2): 49. DOI: 10.3390/buildings7020049.

5. Rovero L, Alecci V, Mechelli J, Tonietti U, De Stefano M. Masonry walls with irregular texture of L'Aquila (Italy) seismic area: validation of a method for the evaluation of masonry quality. Materials and Structures 2016; 49(6): 2297-2314. DOI: 10.1617/s11527-015-0650-2.

6. Giresini L, Sassu M, Butenweg C, Alecci V, De Stefano M. Vault macro-element with equivalent trusses in global seismic analyses. Earthquake and Structures 2017; 12(4): 409-423. DOI: 10.12989/eas.2017.12.4.409.

7. Moon L, Dizhur D, Senaldi I, Derakhshan H, Griffith M, Magenes G, et al. The demise of the URM building stock in Christchurch during the 2010-2011 Canterbury earthquake sequence. Earthquake Spectra 2014; 30(1): 253-276. DOI: $10.1193 / 022113 \mathrm{EQS044M}$.

8. Giresini L. Energy-based method for identifying vulnerable macro-elements in historic masonry churches. Bulletin of Earthquake Engineering 2016; 14(3): 919-942. DOI: 10.1007/s10518-015-9854-7.

9. Abrams DP, AlShawa O, Lourenço PB, Sorrentino L. Out-of-Plane Seismic Response of Unreinforced Masonry Walls: Conceptual Discussion, Research Needs, and Modeling Issues. International Journal of Architectural Heritage 2017; 11(1): 22-30. DOI: 10.1080/15583058.2016.1238977.

10. Casapulla C, Argiento LU. The comparative role of friction in local out-of-plane mechanisms of masonry buildings. Pushover analysis and experimental investigation. Engineering Structures 2016; 126: 158-173. DOI: 10.1016/j.engstruct.2016.07.036.

11. Casapulla C, Portioli F. Experimental tests on the limit states of dry-jointed tuff blocks. Materials and Structures/Materiaux et Constructions 2016; 49(3): 751-767. DOI: 10.1617/s11527-015-0536-3.

12. C. Casapulla; L. U. Argiento. In-plane frictional resistances in dry block masonry walls and rocking-sliding failure modes revisited and experimentally validated. Composites Part B: Engineering 2018; 132: 197-213. DOI: 10.1016/j.compositesb.2017.09.013.

13. Giresini L. Design strategy for the rocking stability of horizontally restrained masonry walls. In: M. Papadrakakis MF, editor. COMPDYN 2017 6th ECCOMAS Thematic Conference on Computational Methods in Structural Dynamics and Earthquake Engineering, Rhodes Island, Greece: 2017.

14. Sorrentino L, Alshawa O, Liberatore D. Observations of out-of-plane rocking in the oratory of san giuseppe dei minimi during the 2009 L'Aquila earthquake. vol. 621, Trans Tech Publications Ltd; 2014. DOI: 10.4028/www.scientific.net/AMM.621.101.

15. Casapulla, C., Giresini, L., Sassu, M., Lourenço PB. Rocking and kinematic approaches of masonry walls: state of the art and recent developments. Buildings 2017. DOI: 10.3390/buildings7030069.

16. Casapulla C. On the resonance conditions of rigid rocking blocks. International Journal of Engineering and Technology 2015; 7(2): 760-771.

17. Casapulla C, Jossa P, Maione A. Rocking motion of a masonry rigid block under seismic actions: a new strategy based on the progressive correction of the resonance response. Ingegneria Sismica 2010; 27(4): 35-48.

18. Casapulla C, Maione A. Free Damped Vibrations of Rocking Rigid Blocks as Uniformly Accelerated Motions. International Journal of Structural Stability and Dynamics 2016; 17(6): 1-19. DOI: 10.1142/S0219455417500584.

19. Doherty K, Griffith MC, Lam N, Wilson J. Displacement-based seismic analysis for out-of-plane bending of unreinforced masonry walls. Earthquake Engineering and Structural Dynamics 2002; 31(4): 833-850. DOI: 10.1002/eqe.126.

20. Derakhshan H, Griffith MC, Ingham JM. Out-of-Plane Behavior of One-Way Spanning Unreinforced Masonry Walls. 
Journal of Engineering Mechanics 2013; 139(4): 409-417. DOI: 10.1061/(ASCE)EM.1943-7889.0000347.

21. Sorrentino L, D’Ayala D, de Felice G, Griffith MC, Lagomarsino S, Magenes G. Review of Out-of-Plane Seismic Assessment Techniques Applied To Existing Masonry Buildings. International Journal of Architectural Heritage 2017; 11(1): 2-21. DOI: 10.1080/15583058.2016.1237586.

22. Housner GW. The behavior of inverted pendulum structures during earthquakes. Bulletin of the Seismological Society of America 1963; 53(2): 403-417. DOI: 10.1017/CBO9781107415324.004.

23. Aslam M, Godden WG, Scalise DT. Earthquake Rocking Response of Rigid Bodies. Journal of the Structural Division 1980; 106(2): 377-392.

24. Makris N, Konstantinidis D. The rocking spectrum and the limitations of practical design methodologies. Earthquake Engineering \& Structural Dynamics 2003; 32(2): 265-289. DOI: 10.1002/eqe.223.

25. Liberatore D., Spera G., D’Alessandro G. ND. Rocking of slender blocks subjected to seismic motion of the base. 12th European conference on earthquake engineering, London: 2002.

26. Sorrentino L, AlShawa O, Decanini LD. The relevance of energy damping in unreinforced masonry rocking mechanisms. Experimental and analytic investigations. Bulletin of Earthquake Engineering 2011; 9(5): 1617-1642. DOI: $10.1007 / \mathrm{s} 10518-011-9291-1$.

27. Costa AA, Arêde A, Penna A, Costa A. Free rocking response of a regular stone masonry wall with equivalent block approach: Experimental and analytical evaluation. Earthquake Engineering and Structural Dynamics 2013; 42(15): 2297-2319. DOI: 10.1002/eqe.2327.

28. Bachmann JA, Strand M, Vassiliou MF, Broccardo M, Stojadinović B. Is rocking motion predictable? Earthquake Engineering \& Structural Dynamics 2018; 47(2): 535-552. DOI: 10.1002/eqe.2978.

29. Derakhshan H, Griffith MC, Ingham JM. Out-of-plane seismic response of vertically spanning URM walls connected to flexible diaphragms. Earthquake Engineering \& Structural Dynamics 2016; 45(4): 563-580. DOI: 10.1002/eqe.2671.

30. Giresini L, Fragiacomo M, Lourenço PB. Comparison between rocking analysis and kinematic analysis for the dynamic out-of-plane behavior of masonry walls. Earthquake Engineering and Structural Dynamics 2015; 44(13): 2359-2376. DOI: 10.1002/eqe.2592.

31. Prajapati S, AlShawa O, Sorrentino L. Out-of-plane behaviour of single-body unreinforced-masonry wall restrained by a flexible diaphragm. COMPDYN 2015 - 5th ECCOMAS Thematic Conference on Computational Methods in Structural Dynamics and Earthquake Engineering, National Technical University of Athens; 2015.

32. Penner O, Elwood KJ. Out-of-plane dynamic stability of unreinforced masonry walls in one-way bending: Parametric study and assessment guidelines. Earthquake Spectra 2016; 32(3): 1699-1723. DOI: 10.1193/011715EQS011M.

33. Penner O, Elwood JE. Out-of-Plane Dynamic Stability of Unreinforced Masonry Walls in One-Way Bending: Shake Table Testing. Earthquake Spectra 2016; 32(3): 1699-1723. DOI: 10.1193/011415EQS009M.

34. Wilson A, Quenneville PJH, Moon FL, Ingham JM. Lateral Performance of Nail Connections from Century-Old Timber Floor Diaphragms. Journal of Materials in Civil Engineering 2014; 26(1): 202-205. DOI: 10.1061/(ASCE)MT.1943-5533.0000792.

35. Giongo I, Dizhur DY, Tomasi R, Ingham JM. Field Testing of Flexible Timber Diaphragms in an Existing Vintage URM Building. Journal of Structural Engineering 2015; 141(1). DOI: 10.1061/(ASCE)ST.1943-541X.0001045.

36. Brignola A, Pampanin S, Podestà S. Experimental Evaluation of the In-Plane Stiffness of Timber Diaphragms. Earthquake Spectra 2012; 28(4): 1687 - 1709. DOI: 10.1193/1.4000088.

37. Andreini M, De Falco A, Giresini L, Sassu M. Mechanical characterization of masonry walls with chaotic texture: procedures and results of in-situ tests. International Journal of Architectural Heritage: Conservation, Analysis, and Restoration 2014; 8(3): 376-407. DOI: 10.1080/15583058.2013.826302.

38. Vasconcelos G, Lourenço PB. Experimental characterization of stone masonry in shear and compression. Construction and Building Materials 2009; 23: 3337-3345. DOI: 10.1016/j.conbuildmat.2009.06.045.

39. CMIT. Circolare del Ministro delle Infrastrutture e dei Trasporti 2 febbraio 2009, n. 617, contenente le Istruzioni per l'applicazione delle "Nuove norme tecniche per le costruzioni" di cui al DM 14 gennaio 20082009.

40. FEMA 356, Prestandard and Commentary for the Seismic Rehabilitation of Buildings, Federal Emergency Management Agency, Washington, D.C. 2000.

41. Giongo I, Wilson A, Dizhur DY, Derakhshan H, Tomasi R, Griffith MC, et al. Detailed seismic assessment and improvement procedure for vintage flexible timber diaphragms. Bulletin of the New Zealand Society for Earthquake Engineering 2014; 47(2): 97-118.

42. MathWorks. Matlab R2016b 2016.

43. Ribeiro GJT, de Castro JGT, Freire JLF. New Improvements in the Digital Double Integration Filtering Method to Measure Displacements Using Accelerometers. Proceedings of The International Society For Optical Engineering 
2001: 538-542.

44. Slifka L. An Accelerometer Based Approach To Measuring Displacement Of A Vehicle Body, MoS Thesis, Department of Electrical and Computer Engineering, University of Michigan-Dearborn. 2004.

45. Chopra AK. Dynamics of Structures. 4th ed. Pearson; 2012.

46. Padoussis MP, Des Trois Maisons PE. Free Vibration of a Heavy, Damped, Vertical Cantilever. Transactions of the American Society of Mechanical Engineers 1971: 524-526.

47. Kalliontzis D, Sritharan S. Characterizing Dynamic Decay of Motion of Free-standing Rocking Members. Earthquake Spectra 2017. DOI: https://doi.org/10.1193/011217EQS013M.

48. Kalliontzis D, Sritharan S, Schultz A. Improved coefficient of restitution estimation for free rocking members. Journal of Structural Engineering 2016; 142(12).

49. Giannini R, Masiani R. Risposta in frequenza del blocco rigido. X AIMETA Conference, Pisa: 1990.

50. Imanishi N, Inoue Y, Shibata K, Sato K, Yamasaki Y. Effect of Base Shape on Damping of Rocking of Rigid Body. Journal of System Design and Dynamics 2012; 6(1): 109-119.

51. Makris N, Konstantinidis D. The rocking spectrum and the limitations of practical design methodologies. Earthquake Engineering and Structural Dynamics 2003; 32(2): 265-289. DOI: 10.1002/eqe.223.

52. Sorrentino L, D’Ayala D, de Felice G, Griffith MC, Lagomarsino S, Magenes G. Review of Out-of-Plane Seismic Assessment Techniques Applied To Existing Masonry Buildings. International Journal of Architectural Heritage 2017; 11(1): 2-21. DOI: 10.1080/15583058.2016.1237586.

53. Luzi L, Puglia R, Russo E, WG5 O. Engineering Strong Motion Database, version 1.0, Istituto Nazionale di Geofisica e Vulcanologia, Observatories \& Research Facilities for European Seismology 2016.

54. Sorrentino L, Masiani R, Decanini LD. Overturning of rocking rigid bodies under transient ground motions. Structural Engineering and Mechanics 2006; 22(3): 293-310. DOI: 10.12989/sem.2006.22.3.293.

55. Dimitrakopoulos EG, DeJong MJ. Overturning of Retrofitted Rocking Structures under Pulse-Type Excitations. Journal of Engineering Mechanics 2012; 138(8): 963-972. DOI: 10.1061/(ASCE)EM.1943-7889.0000410. 